\title{
ANÁLISE DA REATIVAÇÃO DE FALHAS NORMAIS ATRAVÉS DA MODELAGEM FÍSICA COM O USO DO PARTICLE IMAGE VELOCIMETRY.
}

\author{
NORMAL FAULTS REACTIVATION ANALYSIS THROUGH PHYSICAL MODELING \\ USING PARTICLE IMAGE VELOCIMETRY
}

\section{Luís Kennedy Andrade de SOUSA¹, Fernando César ALVES DA SILVA ${ }^{1,2}$, André João P. Conde BLANCO'.}

1Programa de Pós-Graduação em Geodinâmica e Geofísica, Universidade Federal do Rio Grande do Norte, Natal, Rio Grande do Norte, Brasil. E-mails: luiskennedysousa@gmail.com ; ablanco@sapo.pt

${ }_{2}^{2}$ Departamento de Geologia, Universidade Federal do Rio Grande do Norte, Natal, Rio Grande do Norte, Brasil. E-mail: fernando@geologia.ufrn.br

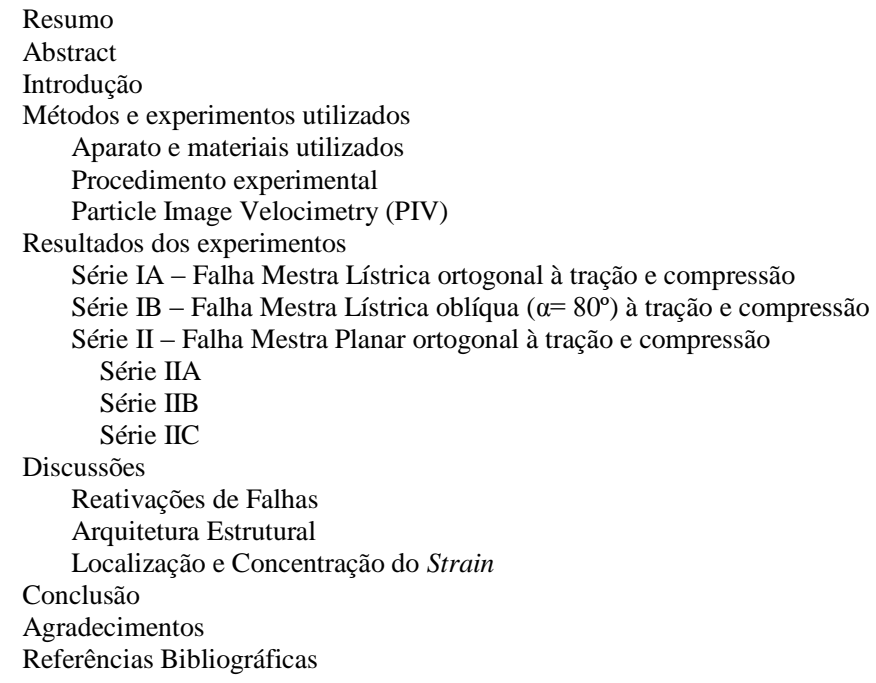

\begin{abstract}
RESUMO: Durante as últimas décadas, a modelagem física tornou-se uma ferramenta importante para melhorar a compreensão de algumas estruturas e processos geológicos, incluindo inversão cinemática das bacias sedimentares. Nesse caso, impulsionado pela industria do petróleo, o melhor conhecimento da inversão positiva se fez necessário, uma vez que este processo poderia gerar (ou destruir) armadilhas para acumulação de hidrocarbonetos. Este artigo trata da relação entre a reativação de falhas normais préexistentes e a geração de novas falhas durante a inversão positiva. Os nossos resultados mostraram que a orientação de falhas e a estratigrafia mecânica podem desempenhar papel importante no processo de inversão positiva, induzindo a reativação de algumas falhas prévias e nucleação de novas falhas. Os experimentos monitorados com o Particle Image Velocimetry (PIV) mostraram em detalhe o comportamento de falhas durante a inversão, evidenciando que o deslocamento ao longo de algumas falhas não é constante, sendo registrado alternância de períodos de atividade e inatividade.
\end{abstract}

Palavras-chave: Inversão positiva, modelagem analógica, estratigrafia mecânica.

\begin{abstract}
During the last decades, physical modeling has become an important tool to improve understanding of some structures and geological processes, including kinematics inversion of the sedimentary basins. In that case, motivated mainly by the petroleum industry, a better knowledge of positive inversion was essential, since this process could produce (or destroy) traps for hydrocarbon accumulation. This article deals with the relationship between the reactivation of pre-existing normal faults and the generation of new ones during a positive inversion. Our results showed that the orientation fault, and mechanical stratigraphy, could play an important role during the process of positive inversion, leading to reactivation of some previous faults as well as determine the geometry of the new ones. The experiments monitored by particle image velocimetry (PIV) shown in detail the fault behavior over D2 event, during which the inversion occurred, revealing that the movement along certain faults are not constant since they show alternating periods of activity and inactivity.
\end{abstract}

Keywords: Positive inversion, analogical modeling, mechanical stratigraphy.

\section{INTRODUÇÃO}

A modelagem analógica, desde o século XIX, vem sendo usada para simular estruturas geológicas com o objetivo de entender os mecanismos que controlam sua geometria e cinemática. $\mathrm{O}$ conceito de inversão estrutural surgiu a partir do estudo em bacias sedimentares portadoras de hidrocarbonetos (Voigt, 1963 segundo Pinto et al., 2010). O termo inversão estrutural positiva descreve a passagem de regime tectônico inicialmente distensional para contracional (Costa et al., 1992), enquanto a inversão estrutural negativa ocorre quando falhas reversas são reativadas com movimento normal (Cooper \& Williams, 1989). O presente trabalho foi direcionado ao estudo de modelos analógicos com inversão positiva. 
Estudos envolvendo a modelagem analógica de inversão de bacias são desenvolvidos para melhorar $\mathrm{o}$ entendimento dos fatores que influenciam na reativação das estruturas préexistentes, bem como sua geometria. Bonini et al. (2012) sugerem, que os vários modelos utilizados para abordar a inversão positiva podem ser agrupados em três tipos: (1) Modelos em que a deformação é analisada no teto da falha, e se utiliza um bloco rígido para induzir a geometria da falha; (2) Modelos puramente rúpteis; e (3) modelos rúpteis-dúcteis, em que se utiliza uma camada dúctil na base do modelo.

Os estudos de modelagem analógica que abordam a inversão positiva utilizam bloco rígido para induzir a geometria da falha (lístrica, planar ou rampa), e o pacote sedimentar representado por areia, argila ou a mistura desses materiais (Buchanan \& Mcclay, 1991; Gomes et al., 2006; Gomes et al., 2010; Keller \& McClay, 1995; Konstatinovskaya, et al., 2007; Koopman et al., 1987; McClay, 1989 segundo McClay, 1995, 1995; Yamada \& McClay, 2003 entre outros). Mesmo com desvantagem, dada pela não deformação do bloco rígido, este tipo de modelo analógico tem desempenhado papel importante para decifrar e validar informações sobre a arquitetura estrutural final e a geometria interna de uma bacia invertida.

Em experimentos onde teto e piso são capazes de sofrer deformação um descontinuador de velocidade (DV) é utilizado na base do modelo (Amilibia et al., 2005; Bonini et al., 2012; Dubois et al., 2002; Pinto et al., 2010; Ventisette et al., 2006). Estes estudos permitiram melhor compreensão da evolução geométrica e cinemática de falhas em ambiente frágil, dentro do contexto de inversão de bacias. A utilização de diferentes materiais granulares para o preenchimento de uma estrutura grabenforme, estabelecendo contraste reológico entre eles, mostra que esta descontinuidade favorece a reativação das falhas da borda e controlam a localização e o mergulho da falha reversa principal, que produz a extrusão mecânica do material (Panien et al., 2005).
Os modelos analógicos também abordam o papel de camadas dúcteis no processo de inversão tectônica (Dubois et al., 2002; Nalpas et al., 1995; Panien et al., 2005; Ventisette et al., 2006). Nesses modelos uma camada de silicone é posicionada ora na base do modelo, ora entre as camadas de areia, ou em ambas as posições, para investigar o efeito da separação do embasamento cristalino da cobertura sedimentar, bem como o papel da orientação das falhas em relação aos campos de tensão atuantes durante a inversão.

Nas últimas décadas novos métodos vêm sendo utilizados na modelagem física, como é o caso do Particile Image Velocimetry (PIV) inicialmente usado para a medição da dinâmica de fluidos e gases (Brossard et al., 2009). A partir de 2001, o PIV foi testado na investigação de processos granulares (White et al., 2001; Wolf et al., 2003) e Adams et al. (2005) o utilizaram em experimentos em "caixa de areia". O PIV fornece a medição exata da deformação não linear complexa, como a distribuição da deformação e o acúmulo de strain ao longo da deformação em 2D e 3D, tanto dentro de zonas deformadas quanto no material circundante (Adam et al., 2005).

O presente estudo é baseado em dois tipos de experimentos: i) somente o teto é capaz de se deformar; ii) o teto e o piso são livres para se deformarem. No primeiro caso foram utilizados blocos de madeira com geometria similar a de uma falha lístrica, enquanto no segundo caso, utilizou-se um descontinuador de velocidade (DV) na base do experimento. Os modelos foram submetidos primeiramente a uma fase de distensão, seguida por uma de contração. $\mathrm{O}$ objetivo destes experimentos foi caracterizar a arquitetura estrutural final de modelo submetido a inversão positiva, verificando a relação entre a geração de novas falhas e a reativação das préexistentes, além de analisar a predisposição de determinadas falhas reativarem, e analisar os fatores que possam controlar essa predisposição. Adicionalmente, efetuou-se a análise do comportamento e distribuição do strain ao longo do processo deformacional a partir de imagens obtidas e processadas pelo sistema PIV.

\section{MÉTODOS E EXPERIMENTOS REALIZADOS}

\section{Aparato e materiais utilizados}

O aparato tipo "caixa de areia" utilizado, consiste em uma caixa de vidro, retangular (52 $\mathrm{cm} \times 34 \mathrm{~cm} \times 24 \mathrm{~cm}$ ), com três paredes fixas e uma móvel. A parede móvel, acoplada a um motor elétrico, movimentou-se com velocidade constante de $0,42 \mathrm{~mm} / \mathrm{s}$, tanto na tração quanto na compressão. $\mathrm{Na}$ base da caixa foi colocada uma 
folha de papel fixada à parede móvel. Duas séries de experimentos foram realizadas (Figura 1):

Série I - Na extremidade oposta à parede móvel, foram colocados blocos de madeira com diferentes geometrias para simular/induzir a formação de uma falha mestra. Durante a fase de compressão a folha de papel foi descolada da parede móvel. Analisou-se a geração de falhas associadas a geração da falha lístrica principal e sua reativação durante a inversão cinemática. Nesta série, dois tipos de modelos foram realizados: um com a falha lístrica, ortogonal a direção de tração e compressão (Série IA), e outro com falha lístrica oblíqua com ângulo " $\alpha$ " igual a $80^{\circ}$ (Série IB).

Série II - Realizado sem a utilização de blocos de madeira, uma folha de papel na base do modelo funcionou como o descontinuador de velocidade. Nesta série analisou-se a geração de falhas associadas à formação da falha mestra planar, ortogonal à direção de tração/compressão. Nestes experimentos procurou-se também observar o papel da reologia na predisposição de falhas normais serem reativadas.
Para representar a sequência pré-tectônica na Série I, utilizou-se camadas intercaladas de areia natural $(1,0 \mathrm{~cm}$ de espessura) e areia tingida artificialmente $(0,5 \mathrm{~cm}$ de espessura), para servir de marcador tectônico. A espessura total foi de $7 \mathrm{~cm}$. Em todos os modelos utilizados, a distensão total foi de $8 \mathrm{~cm}$, e a contração foi de $11 \mathrm{~cm}$.

$\mathrm{Na}$ Série II, três tipos de experimentos foram realizados com pacotes pré-tectônicos constituídos por diferentes tipos de materiais: (i) apenas areia; (ii) areia e gesso; (iii) areia e argila. As camadas de areia natural tinham espessura de $1,5 \mathrm{~cm}$ ou $1 \mathrm{~cm}$ intercaladas com camadas de areia tingida com $0,5 \mathrm{~cm}$ de espessura, ou camadas de gesso ou argila com $1,5 \mathrm{~cm}$ de espessura. A espessura total variou entre 6 e $7 \mathrm{~cm}$ e a distensão e contração total foram similar a série I. Durante o evento de inversão cinemática, em ambas as séries, foi utilizado o PIV para obtenção de fotografias de alta resolução e seu tratamento foi feito através do software DaVis8 e LaVision.

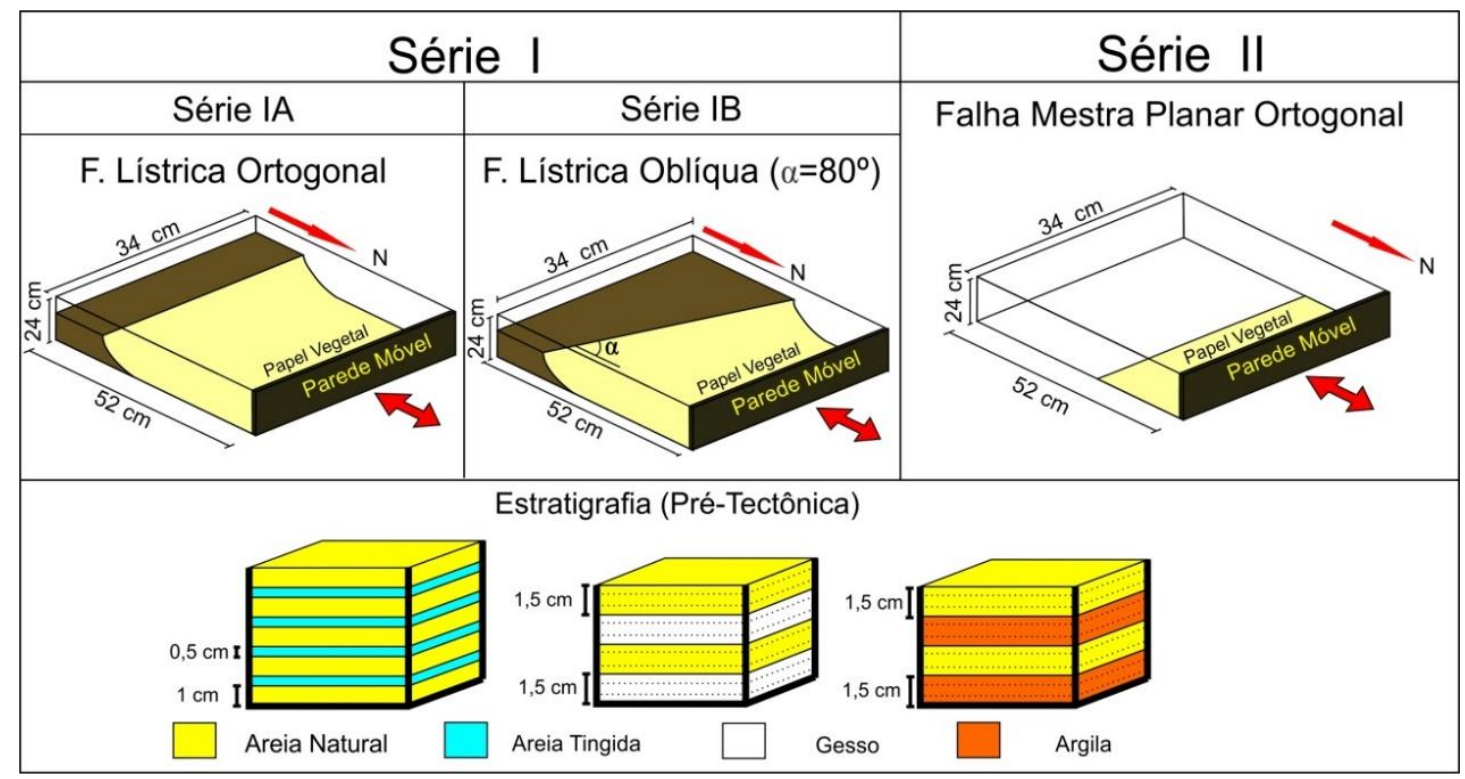

Figura 1. Esquema mostrando a caixa antes da colocação da areia. Papel vegetal recobre a base e blocos de madeira, representando um bloco rígido e induzem a formação da falha lístrica ortogonal e oblíqua (Série I) e da falha planar (Série II). A estratigrafia da sequência pré-tectônica também é mostrada.

\section{Procedimento Experimental}

Para verificar a reprodutibilidade das estruturas geradas, os modelos foram realizados pelo menos duas vezes, mantendo-se as mesmas condições de contorno. Durante a tração (evento D1) a cada intervalo de $0,5 \mathrm{~cm}$ foi adicionada areia tingida simulando sedimentação sintectônica. $\mathrm{O}$ evento compressional (D2), foi realizado sem sedimentação sintectônica.

$\mathrm{O}$ registro dos vários incrementos deformacionais foi feito em intervalos constantes (a cada $0,5 \mathrm{~cm}$ ) através de fotografias tiradas sequencialmente nas laterais da caixa de areia. Nos experimentos da Série IB, fotografias foram obtidas também da 
superfície do modelo, que, após a compressão, foi endurecido e seccionado gerando 12 seções paralelas a direção de distensão/contração. Nas fotografias obtidas com a câmera fotográfica comum, não foi possível visualizar parte da base da seção pré-tectônica devido ao suporte que prende as paredes da caixa. Assim, nestas fotos, foi colocada uma faixa branca.

\section{Particle Image Velocimetry (PIV)}

Neste trabalho, foram obtidos dados em 2D da evolução do strain ao longo dos experimentos. O acompanhamento dos experimentos das Séries I e II com o PIV possibilitou avaliar em detalhe, a evolução da deformação ao longo do tempo. $\mathrm{O}$ processamento das imagens obtidas durante os vários incrementos deformacionais permitiu identificar locais onde a deformação se concentrou em dado intervalo de tempo e a sua migração ao longo do processo deformacional. Três tipos de dados foram obtidos com o sistema PIV, o primeiro mostra os vetores de velocidade absoluta do material granular, o segundo mostra a distribuição do strain ao longo da deformação e o terceiro mostra os campos de magnitude de deslocamento.

\section{RESULTADOS E DISCUSSÃO}

Série IA - Falha Mestra: Lístrica ortogonal à tração e compressão

\section{Evento Distensional (D1)}

A formação da falha lístrica e a nucleação de uma falha antitética ocorreram logo nos primeiros estágios de deformação. As camadas pré-tectônicas foram basculadas contra a falha lístrica e com o aumento da deformação e sedimentação sintectônica, houve o desenvol-vimento de uma estrutura rollover clássica com crescimento da seção sintectônica em direção à falha lístrica (Figura 2A). Com a progressão da deformação houve aumento no crescimento da seção sintectônica, no basculamento das camadas e as falhas sintéticas à falha lístrica foram rotacionadas e se tornam mais sinuosas, principalmente quando cortam as sequências sintectônicas. Duas pequenas falhas reversas, com vergência contrária à falha lístrica, se desenvolveram a partir de $32 \%$ de deformação (Figura 2B).

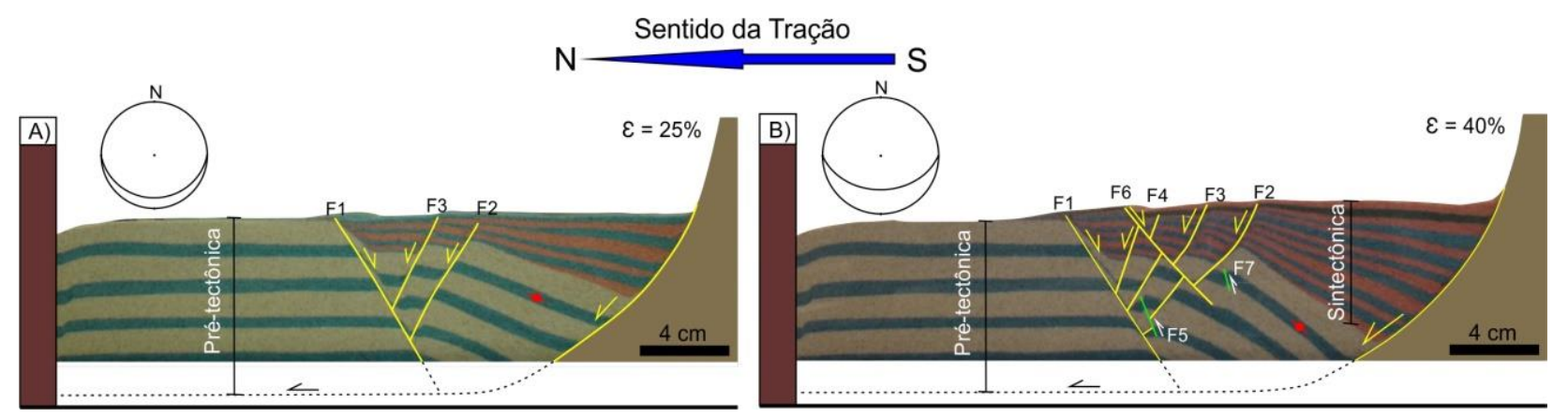

Figura 2. Exemplos de dois estágios da deformação D1 na Série IA: (A) Formação de rollover mostrando o crescimento da seção e o basculamento das camadas. (B) Estágio final da distensão, com o desenvolvimento de falhas antitéticas seccionando às sintéticas. Os diagramas mostram o mergulho das camadas pré-tectônicas medido em camada guia, assinalada por um ponto vermelho nos perfis.

\section{Evento Contracional (D2)}

A inversão cinemática foi realizada a partir da compressão horizontal do modelo após $40 \%$ de distensão (estágio mostrado na figura 2B). O evento D2 foi realizado sem sedimentação sintectônica. O primeiro sinal de inversão positiva foi registrado na falha lístrica com o desenvolvimento de estrutura tipo "arpão" nas camadas adjacentes à falha (Fig. 3A).

$\mathrm{O}$ desenvolvimento de falhas reversas teve início em torno de $14 \%$ de contração, com a nucleação do retroempurrão (F8) na sequência pré-D1, com ângulo de mergulho mais baixo que a falha normal da extremidade norte do modelo, e o empurrão (F9), com vergência para sul, nucleado na sequência D1 (Fig. 3B). Novas falhas reversas, com ângulo de mergulho entre $25^{\circ}$ a $30^{\circ}$, desenvolvidas na porção norte do modelo seccionaram as falhas normais ali préexistentes, quando o encurtamento alcançou 25\% (Fig. 3C). A falha lístrica continuou ativa (reativada), amplificando a estrutura em arpão (Fig. 3C).

Enquanto os retroempurrões desenvolvidos na sequência pré-D1 se enraizaram na parte de mergulho mais baixo da falha lístrica (Fig. 3D), 
empurrões menores evoluíram a partir da sequência sin-D1 e, junto com os retroempurrões, soerguem esta parte do modelo (Figuras 3D e 3E), com geração localizada de pop-up na sequência pré-D1 (Figura 3E).

Durante todo o processo deformacional a falha lístrica esteve ativa e grande parte da contração foi acomodada na inversão positiva desta estrutura e no desenvolvimento dos retroempurrões. A parte central do modelo foi elevada, flanqueada pela falha lístrica na porção sul e os retroempurrões na porção norte. A interação das falhas reversas com as falhas normais préexistentes resultou em complexidade estrutural significativa. As falhas normais geradas durante D1 foram rotacionadas no sentido anti-horário durante o evento D2, sendo seccionadas pelas falhas reversas, gerando vários segmentos, mas nenhumas delas (a exceção da lístrica) foi invertida cinematicamente.

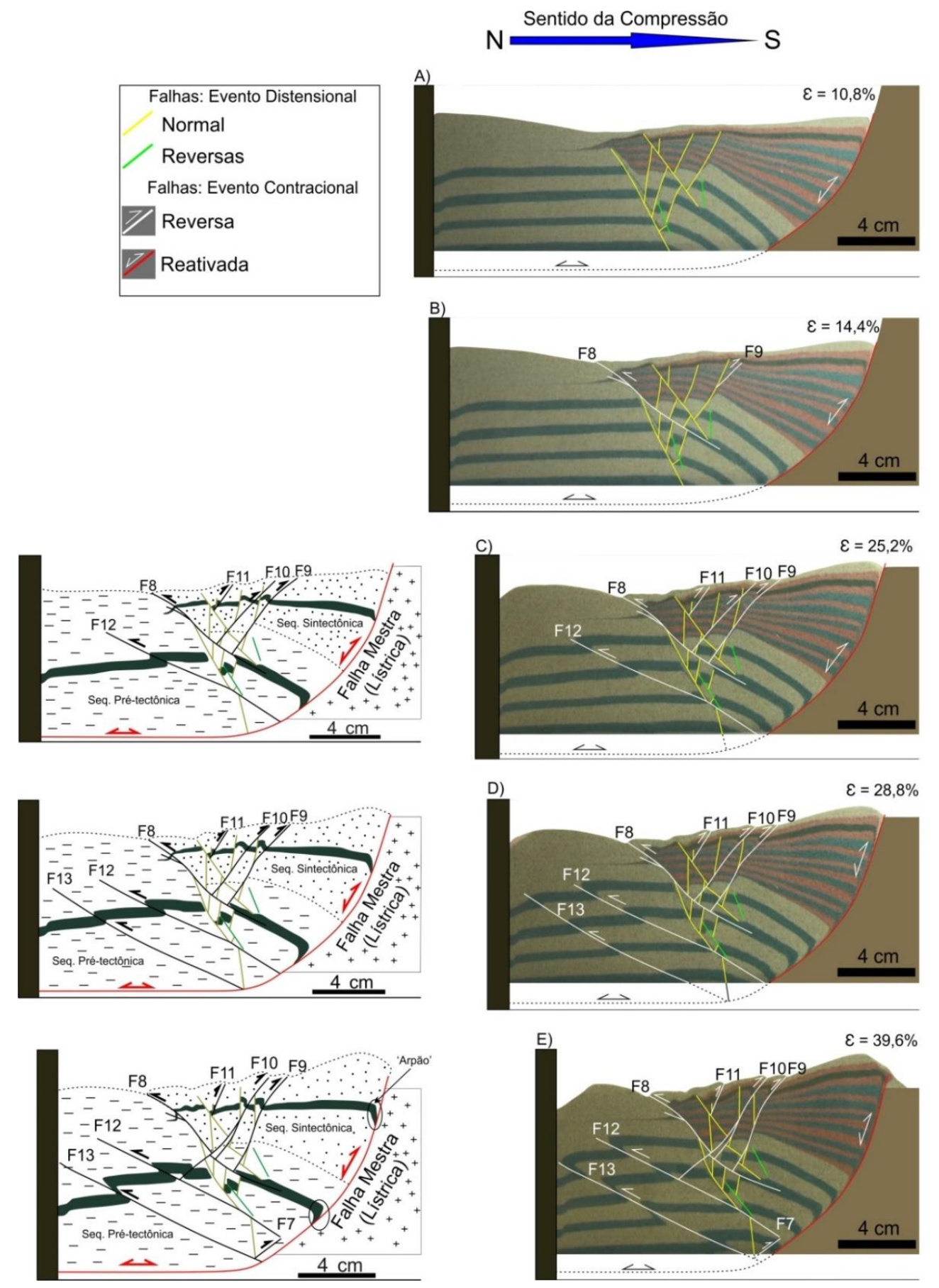

Figura 3. Ilustração de alguns estágios da deformação D2 na Série IA. (A) Início da inversão positiva da falha lístrica, com desenvolvimento de estrutura tipo "arpão". (B) Desenvolvimento das primeiras falhas reversas com vergências opostas. (C) e (D) Falhas reversas seccionam as normais pré-existentes. Notar a ampliação da estrutura "arpão". (E) Estágio final do evento D2, com falhas normais rotacionadas e seccionadas por pelas falhas reversas, aumentando a complexidade estrutural. 
Série IB - Falha Mestra Lístrica oblíqua $\left(\alpha=80^{\circ}\right)$ à tração e compressão

Devido à obliquidade da falha lístrica, neste modelo os lados Leste, onde a falha estava mais próxima à parede móvel e Oeste, onde a falha estava mais distante (cf. Figura 1), foram analisados separadamente, embora apenas a deformação do lado Leste seja descrita aqui em maior detalhe.

\section{Evento Distensional (D1)}

Nos primeiros incrementos deformacionais (4\% de distensão) duas falhas se desenvolveram, a falha lístrica e uma falha normal antitética de alto ângulo de mergulho (F1), nucleada na base da sequência. Com a progressão da deformação e adição da sedimentação sintectônica, um sinclinal rollover, desenvolveu-se associado à falha lístrica enquanto a falha $\mathrm{F} 1$ rotacionou, diminuindo seu ângulo de mergulho. Um sistema de falhas sintéticas à falha lístrica foi desenvolvido na base da seção pré-D1, enquanto no topo da sequência nova falha antitética (F6) se desenvolveu, gerando estrutura grabenforme (Figura 4A). Nos estágios de deformação mais avançados (Figura 4B), a falha antitética F6 se propagou para a base da sequência, seccionando as falhas sintéticas mais antigas, gerando estruturação mais complexa na porção do modelo oposta a falha lístrica.

Durante o evento distensional a deformação do lado Oeste do experimento foi marcada por pelo desenvolvimento de um número menor de falhas.

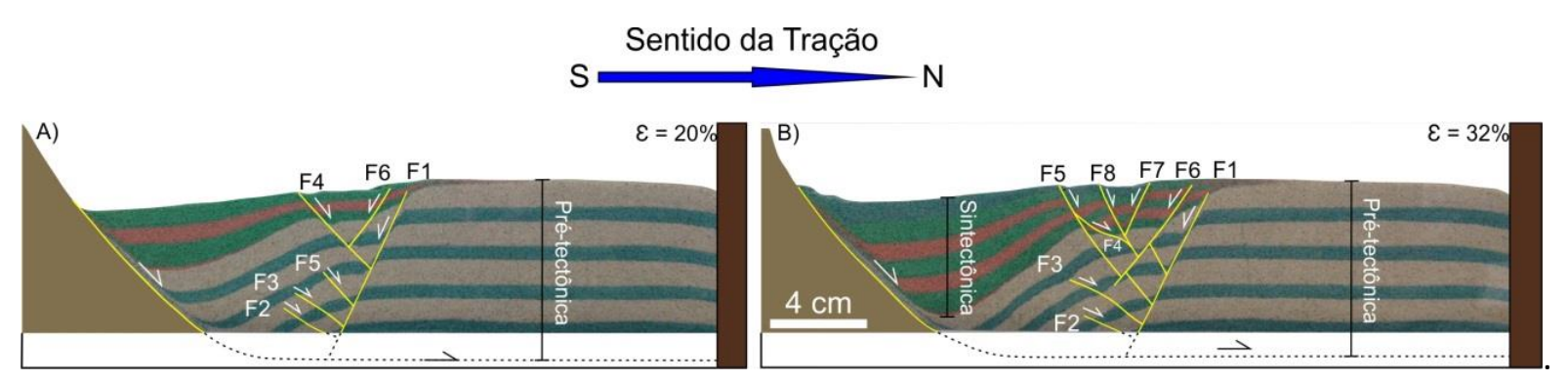

Figura 4. Dois estágios deformacionais do evento D1 na Série IB. (A) Formação da falha lístrica e o desenvolvimento de falhas normais sintéticas à falha lístrica, principalmente na base da sequência pré-tectônica. (B) No estágio final da distensão a falha F6 se propagou para a base da sequência e seccionou as falhas sintéticas à falha lístrica

\section{Evento Contracional (D2)}

O início do evento contracional foi marcado pela reativação, como falha inversa, do segmento superior da falha F5, da falha antitética F7, e o desenvolvimento da falha reversa $\mathrm{F} 9$ na base do modelo (Figura 5A). A inversão cinemática da falha lístrica teve início antes da contração atingir $8 \%$ mas torna-se mais perceptível a partir deste momento (Figura 5B). Neste estágio, algumas falhas antitéticas (F1 e F6) e sintética (F3) à falha lístrica, também foram reativadas.

Empurrões com geometria em splay (F9 e F11), enraizando-se no décollement associado à falha lístrica e retroempurrões (F10 e F13) desenvolveram-se à medida que a deformação aumentou (Figura 5C). A partir deste estágio, toda a deformação foi concentrada na geração de falhas reversas, cessando a reativação das falhas normais relacionadas ao evento D1 (Figuras 5D e 5E). Alguns segmentos das falhas normais (F4 e F5), entre as falhas F1 e F6, sofreram rotação durante D2, invertendo a polaridade do mergulho (Comparar figuras 5A e 5E).
No lado Oeste a falha lístrica quando reativada exibiu o desenvolvimento de estrutura tipo "arpão" sobrepondo-se as estruturas de arrasto criadas no evento D1 e ainda visível em alguns estágios deformacionais, mas praticamente apagadas nos estágios finais da deformação (Figura 6).

Os dados de vetores de velocidade, obtidos com o PIV, mostraram que a deformação foi absorvida primeiramente pela porção do experimento junto ao backstop, reativando e criando novas falhas, nesta extremidade do modelo (Figuras 7A e 7B). Estes vetores atingem a falha lístrica em cerca de $5,6 \%$ de encurtamento, marcando o início da inversão cinemática desta falha (Figura 7C).

Os dados de distribuição do strain (lado Leste do modelo) mostraram que em $14 \%$ de encurtamento, a deformação estava concentrada em três falhas, o retroempurrão F10 e as falhas reversas F9 e F11, esta última exibiu geometria curva subparalela a falha lístrica (Figura 7D) que neste estágio estava inativa. Estes dados mostraram ainda que as falhas F9 e F10 tornaram- 

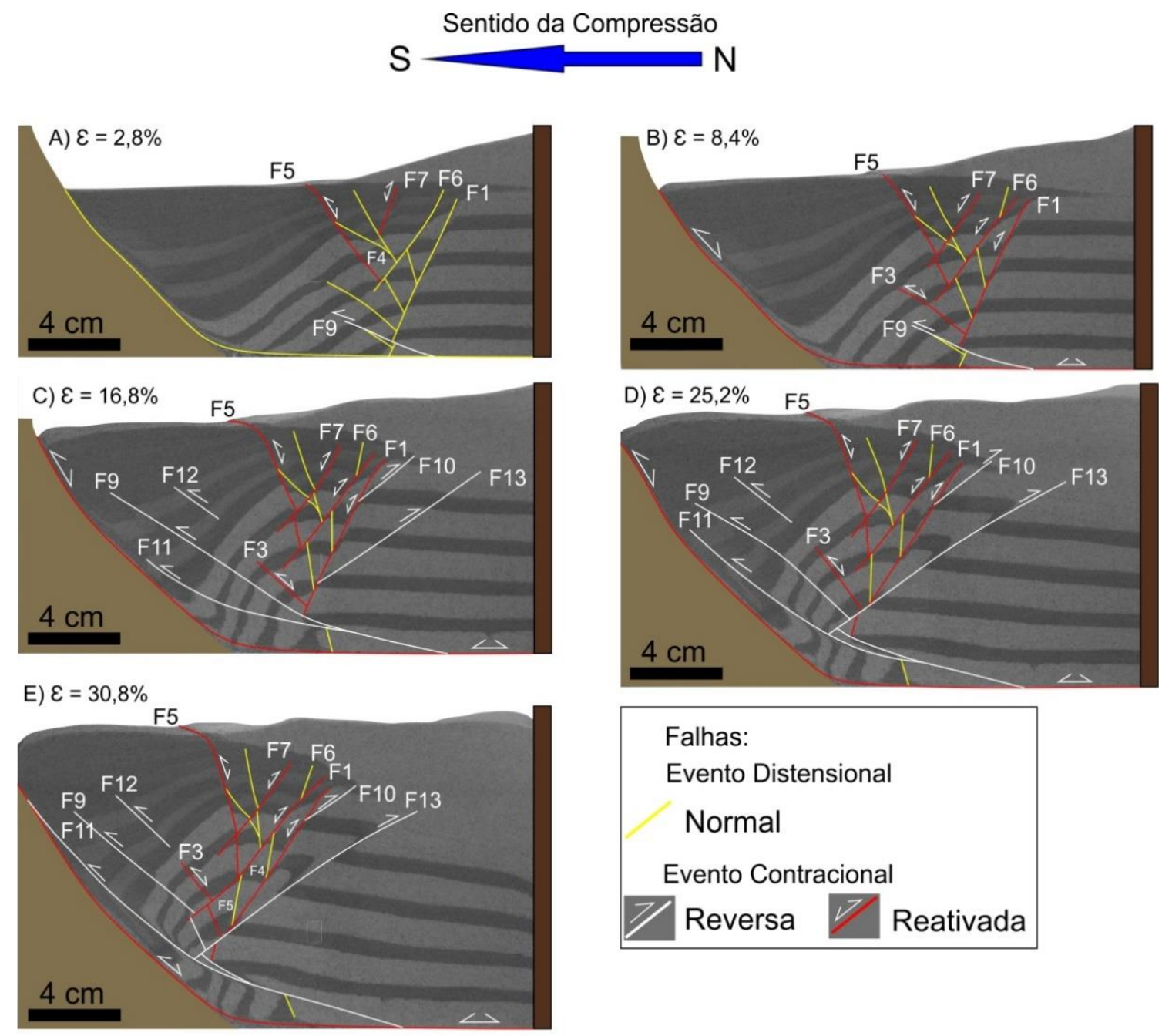

Figura 5. Ilustração de alguns estágios da deformação D2 na Série IB. (A) Reativação, com inversão cinemática, das falhas F5 e F7 logo nos primeiros incrementos deformacionais. (B) Reativação das falhas antitéticas (F1 e F6), concomitante a reativação da falha lístrica. (C) Desenvolvimento de falhas com geometria tipo splay (F9 e F11) além de retroempurrões (F10 e F13). (D) A propagação do retroempurrão F13, para a base da sequência, seccionou o empurrão F9. (E) Segmentos de falhas normais não reativadas entre as falhas F1 e F6, mostram inversão do mergulho devido ao processo de rotação.

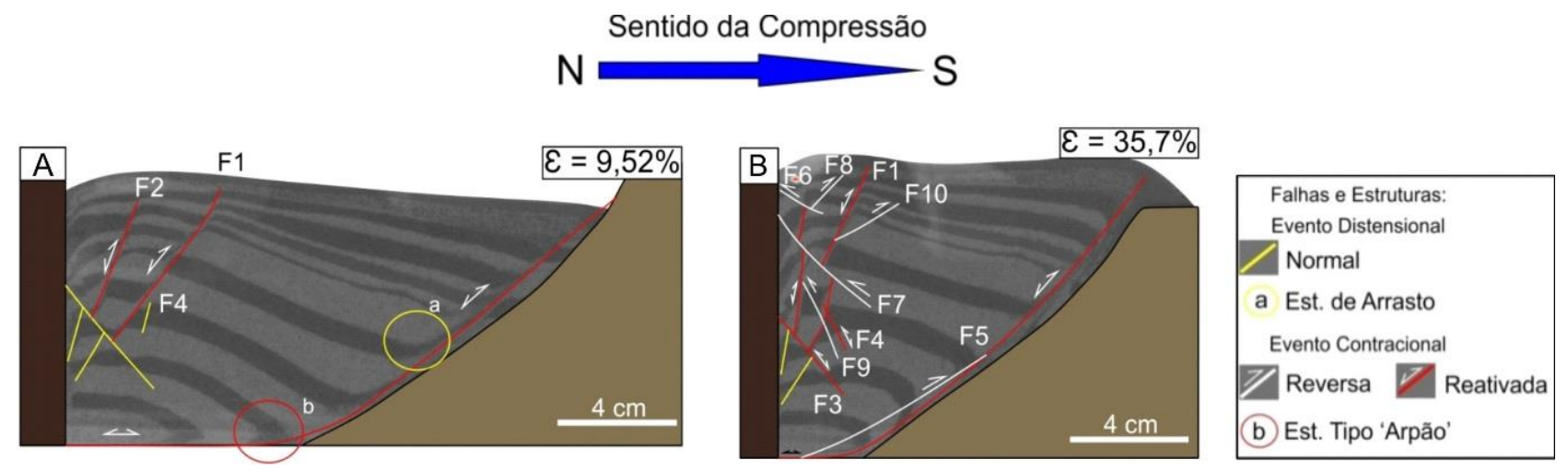

Figura 6. Reativacão da falha lístrica no lado Oeste do experimento na Série IB. (A) Estrutura do tipo arpão, associada ao evento contracional, começaram a se desenvolver na parte basal da falha lístrica. (B) No estágio final da deformação, estruturas do tipo arpão ocorrem ao longo de toda a falha lístrica, marcando sua completa inversão positiva.

se inativas quando da geração e desenvolvimento da falha F13, que também inibiu a nucleação da falha reversa F12, enquanto a falha F3 era reativada (embora com pouca variação de rejeito) (Figura 7E). Em cerca de 30\% de encurtamento, a deformação estava concentrada quase que exclusivamente na inversão da falha lístrica, na falha reversa F11, além da nucleação do retroempurrão F14, observado apenas com os dados do PIV (Figura 7F). 


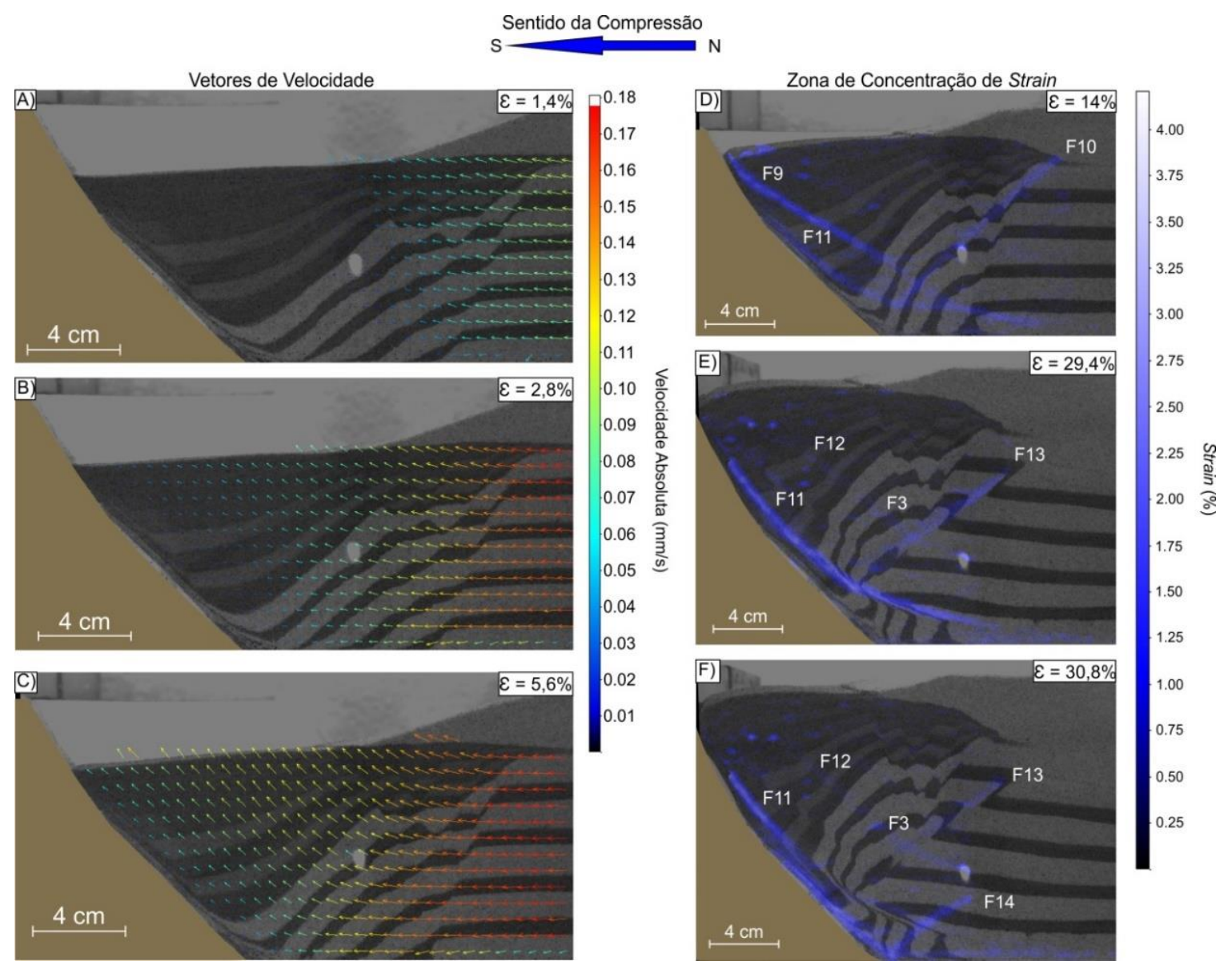

Figura 7. Ilustrações dos dois tipos de dados obtidos com PIV em experimentos da Série IB: vetores de velocidade (A a C) e zonas de concentração de strain (D a F). (A) e (B) Mostram a progressão da deformação em direção à falha lístrica. (C) Registra a chegada da deformação na falha lístrica, reativando-a com cinemática inversa. (D) A concentração da deformação (faixas azuis) mostra as falhas ativas (F9, F10 e F11) neste estágio deformacional. (E) Nucleação do retroempurrão F13 e pequena reativação da falha F3. (F) Neste estágio, ocorreu a reativação da falha lístrica e nucleação da falha F14, que é vista apenas nos dados do PIV. (A mancha que aparece no centro da figura A e nas demais, trata-se de reflexo da câmera).

No lado Oeste do experimento, os dados de PIV mostraram que a falha lístrica iniciou sua inversão positiva antes dos $10 \%$ de compressão e esteve ativa durante todo o evento D2 e, nos últimos estágios deformacionais, concentrou a maior parte da deformação (Figura 8).

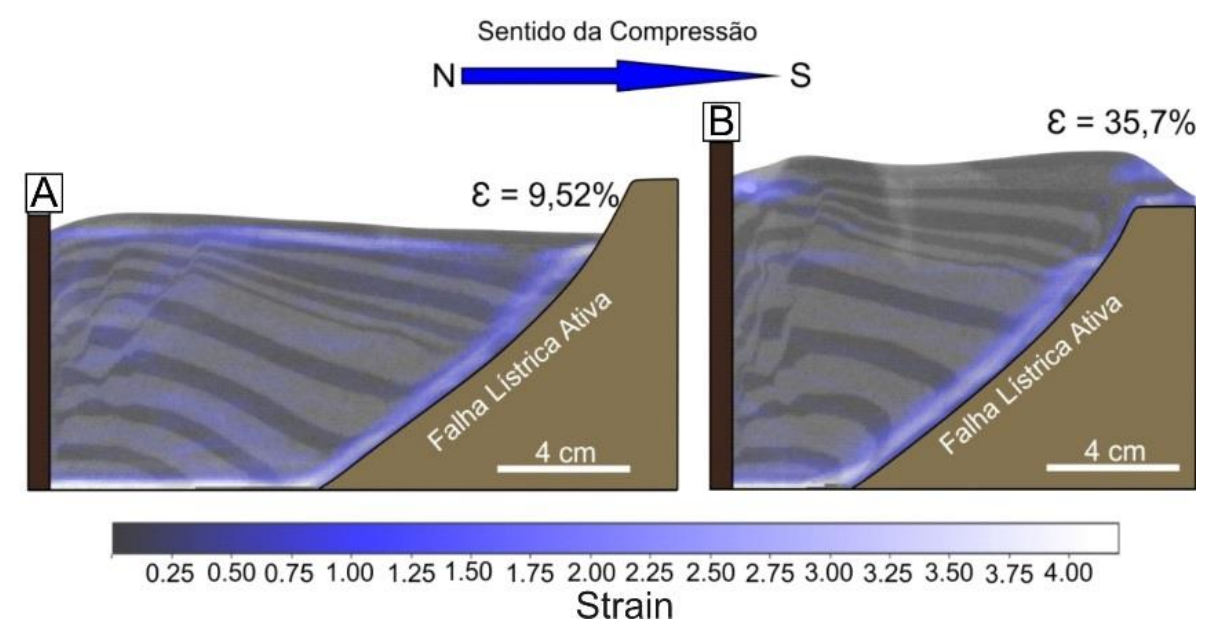

Figura 8. Zonas de concentração de strain (faixas azuis) em dois estágios da deformação contracional no lado oeste do modelo da Série IB. (A) e (B) mostram que a falha lístrica foi reativada, como falha reversa, e esteve ativa em quase todo o evento deformacional e concentrou a maior parte da deformação nos estágios finais da deformação D2. A zona azul, sub-horizontal no topo do modelo em (A), não representa deformação no perfil, trata-se de pequena porção da superfície do modelo imageado pela câmera do PIV. 


\section{Série II - Falha Mestra: Planar ortogonal à tração e compressão}

Esta série de experimentos foi realizada com variação reológica entre as camadas constituintes da sequência pré-tectônica (areia, gesso e argila). A denominação Série IIA, IIB e IIC, foi dada em função dos materiais empregados.

\section{Série IIA}

Para servir de padrão, na comparação com os demais materiais utilizados, nesta série utilizou-se apenas areia (coloração natural e tingida).

\section{Evento distensional (D1)}

Falhas planares, com mergulhos fortes e opostos, foram desenvolvidas nos primeiros estágios da deformação, dando origem a uma estrutura grabenforme, com as camadas prétectônicas basculadas para sul, contra a falha F1 (Figuara 9A). Com o aumento da distensão, um conjunto de falhas normais, fora de sequência, foi gerado. A interação entre as falhas F1/F4 e F7/F8 gerou estrutura tipo "cavalo" nas porções sul e central da estrutura grabenforme (Figura 9B). Neste experimento, não foi observada a rotação das falhas.

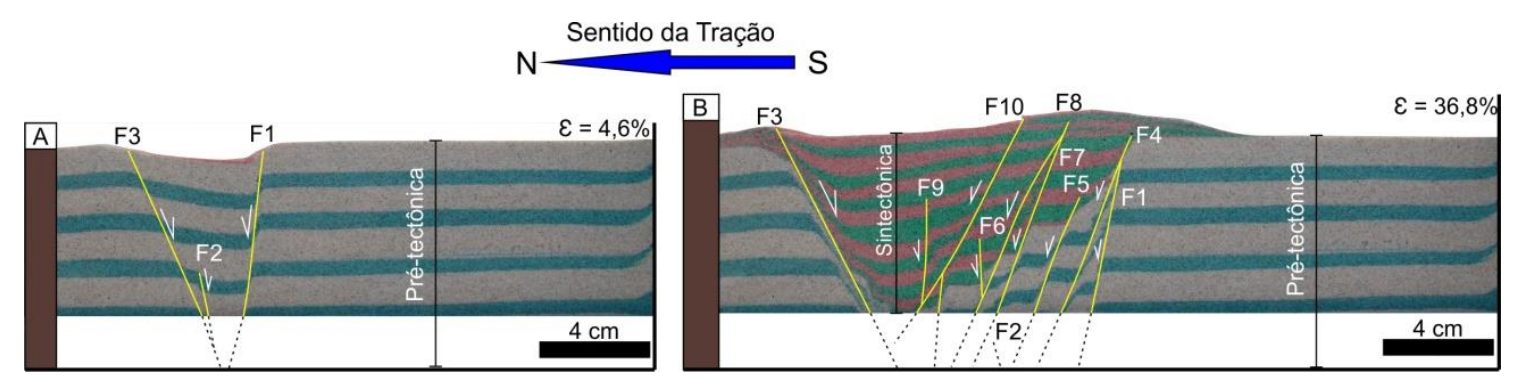

Figura 9. Ilustração de dois estágios da deformação D1 em experimento da Série IIA. (A) Falhas planas, definindo uma estrutura grabenforme nos estágios iniciais da deformação. (B) Estágio final do evento D1, mostrando "cavalos" tectônicos na porção mais a sul da estrutura grabenforme.

\section{Evento contracional (D2)}

As primeiras evidências visíveis deste evento foi a inversão das falhas normais delimitadoras do depocentro da estrutura grabenforme gerada em D1 (F3 e F10), e duas outras (F4 e F8), na extremidade sul do modelo (Figura 10A). Os dados de PIV (vetores de velocidade) confirmam este cenário inicial de
D2 (Figura 11). Depois deste estágio nenhuma outra falha foi reativada, sendo a deformação representada pelo desenvolvimento de novas falhas (F11 a F13), agora com ângulo de mergulho bem mais baixo do que àquelas reativadas. Elas mostraram cinemática reversa e seccionaram as falhas normais pré-existentes (Figura 10B).

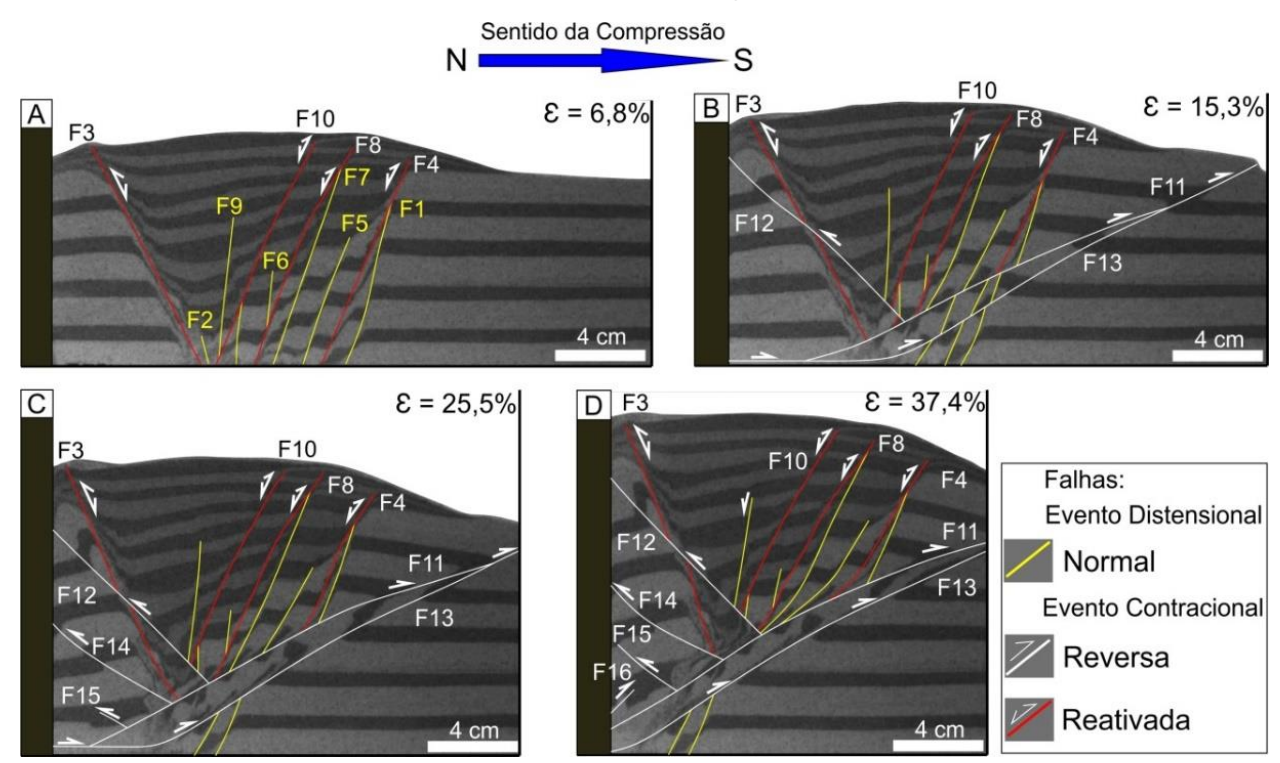

Figura 10. (A) Em experimento da Série IIA, a deformação D2 foi inicialmente representado pela reativação das falhas F3, F4, F8 e F10. (B) Desenvolvimento de falhas reversas (empurrões F11 e F13 e retroempurrão 12). (C) Desenvolvimento de retroempurrões, no compartimento basal do modelo, acima do empurrão F11. D) Estágio final da deformação, mostrando que grande parte das falhas normais não sofreram modificação em sua geometria durante o evento D2. 
Os empurrões se enraizaram no deslocamento basal enquanto o retroempurrão ficou limitado pela falha F11 (Figura 10B). Nos incrementos deformacionais subsequentes apenas retroempurrões foram formados, mas os empurrões F11 e F13, que definem o "cavalo" tectônico, continuaram ativos, ampliando a separação entre os segmentos das falhas normais por eles seccionados (Figuras 10C e 10D).

Os dados de strain obtidos com o PIV ratificam a concentração da deformação ao longo dos empurrões F11 e F13 e do retroempurrão 12 a partir de $15 \%$ de encurtamento (Figura 11C). Estes dados mostram ainda a competição/partição da deformação entre as falhas novas e antigas. $\mathrm{O}$ desenvolvimento de nova zona de deformação, marcando a nucleação do retroempurrão F14, tornou o empurrão $\mathrm{F} 11$ inativo e houve o arrefecimento na movimentação do retroempurrão F12 (Figura 11D). A geração do retroempurrão F15 (entre $22 \%$ a $32 \%$ de compressão) provocou acentuada diminuição da atividade do retroempurrão $\mathrm{F} 14$, a inatividade do retroempurrão $\mathrm{F} 12$, e a retomada da movimentação do empurrão F11 (Figuras 11E e 11F). Até o fim da deformação, as falhas normais não reativadas comportaram-se de forma passiva nos blocos soerguidos pelas falhas reversas, sem sofrerem rotação.
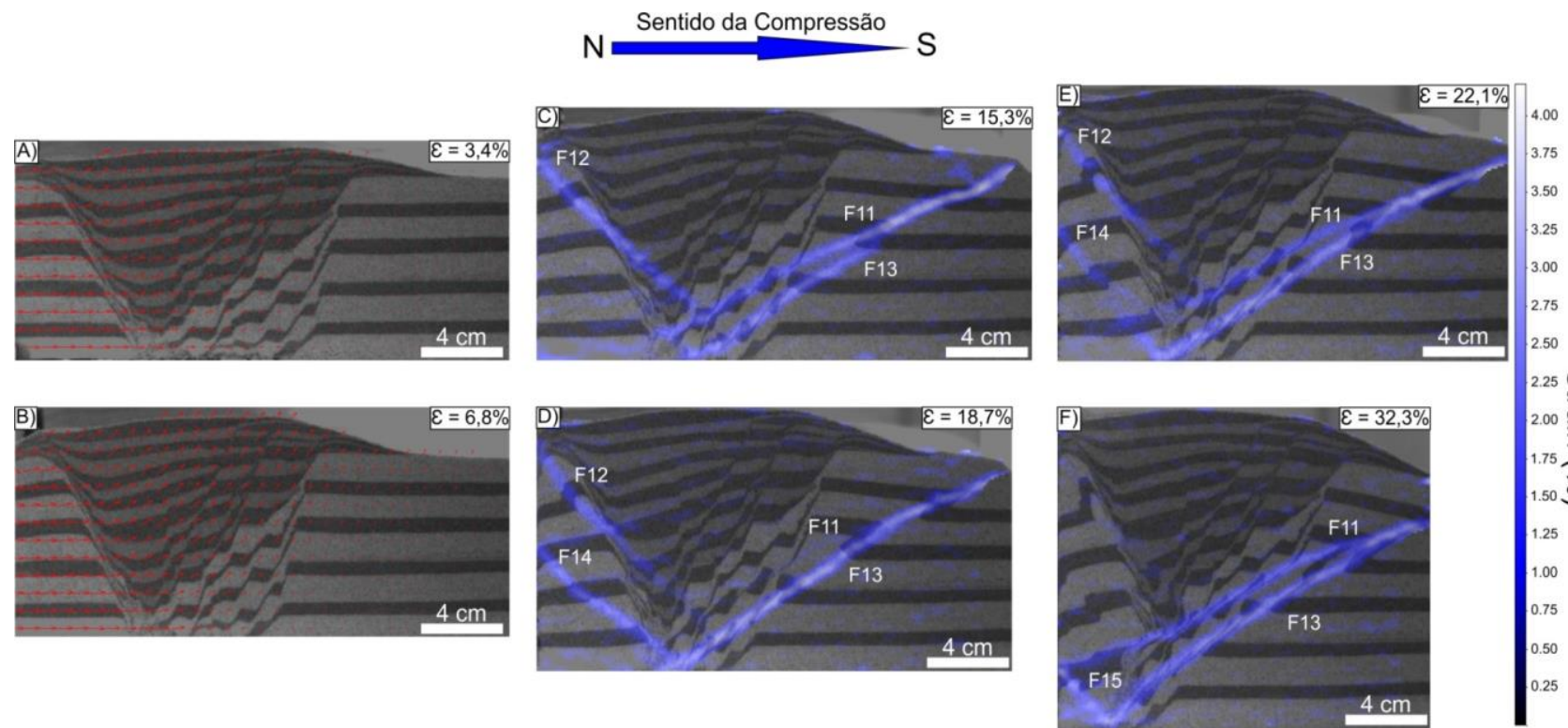

Figura 11. Imagens dos dois tipos de dados obtido com PIV para a Série IIA durante o evento D2. (A) e (B) mostram os vetores de velocidade em dois estágios deformacionais. Durante o início do encurtamento, parte da deformação foi absorvida pela compactação do material seguindo-se a reativação das falhas primeiramente as mais a norte e depois as mais a sul do modelo. (C) a (F) mostram as zonas de concentração da deformação (zonas azuis). (C) Concentração da deformação delineando os empurrões F11 e F13 e do retroempurrão F12. (D) O empurrão F11 ficou inativo durante o desenvolvimento do retroempurrão F14. (E) O empurrão F11 voltou a ficar ativo enquanto a movimentação ao longo de F14 diminuiu. (F) Desenvolvimento do retroempurrão F15 enquanto F12 e F14 tornaram-se praticamente inativos

\section{Série IIB}

Neste experimento foram introduzidas duas camadas de pó de gesso, intercaladas às camadas de areia de coloração natural, no sentindo de criar uma anisotropia reológica.

\section{Evento distensional (D1)}

Como no experimento anterior, falhas normais com mergulho opostos foram desenvolvidas, nos primeiros incrementos deformacionais (Figura 12A). Com o aumento da distensão, novas falhas, fora de sequência, foram geradas, no interior da estrutura grabenforme. Uma destas falhas (F5) propagouse na sequência sintectônica acima de F1, delimitando, em superfície, a borda sul da estrutura grabenforme. A configuração final do experimento mostrou conjunto de falhas com ângulo de mergulho entre $60^{\circ}$ a $70^{\circ}$ (Figura 12B). De forma geral, há pequeno aumento do mergulho das falhas quando elas atravessaram a camada de gesso. Uma estruturação particular foi formada na parte basal do modelo, com o desenvolvimento de dobras formadas a partir do arrasto das camadas junto às falhas normais (Figura 12B).

\section{Evento contracional (D2)}

A inversão positiva foi inicialmente marcada pela reativação como falhas reversas, de 
segmentos superiores, de ângulo baixo, das falhas F5 e F10 (Figura 13A) e o desenvolvimento das falhas reversas F14 e F15, respectivamente na base e topo do modelo. Com o aumento da deformação, duas novas falhas reversas foram nucleadas, F16 propagada a partir do descolamento basal, e F17, na parte superior, limitada pela falha normal F1 (Figura 13B).

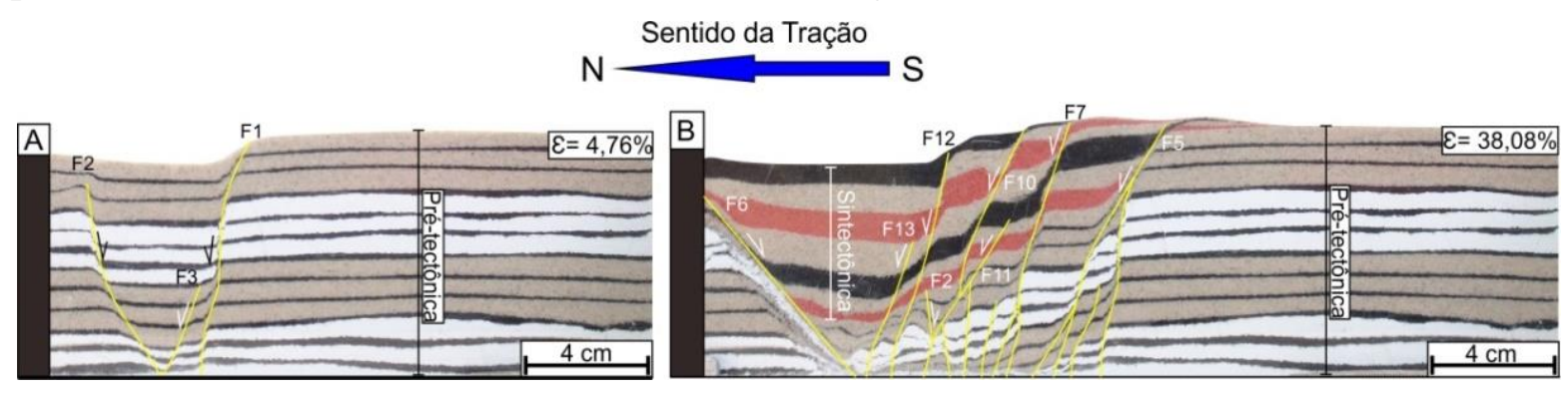

Figura 12. Estágios inicial e final do evento D1 em experimento da Série IIB. (A) Geração de falhas normais com ângulo de mergulho opostos, delineando uma feição grabenforme. (B) Estágio final do evento D1, com desenvolvimento de falhas fora de sequência. O conjunto de falhas normais exibe ângulo de mergulho médio a alto e um arranjo mais complexo na parte basal do modelo.

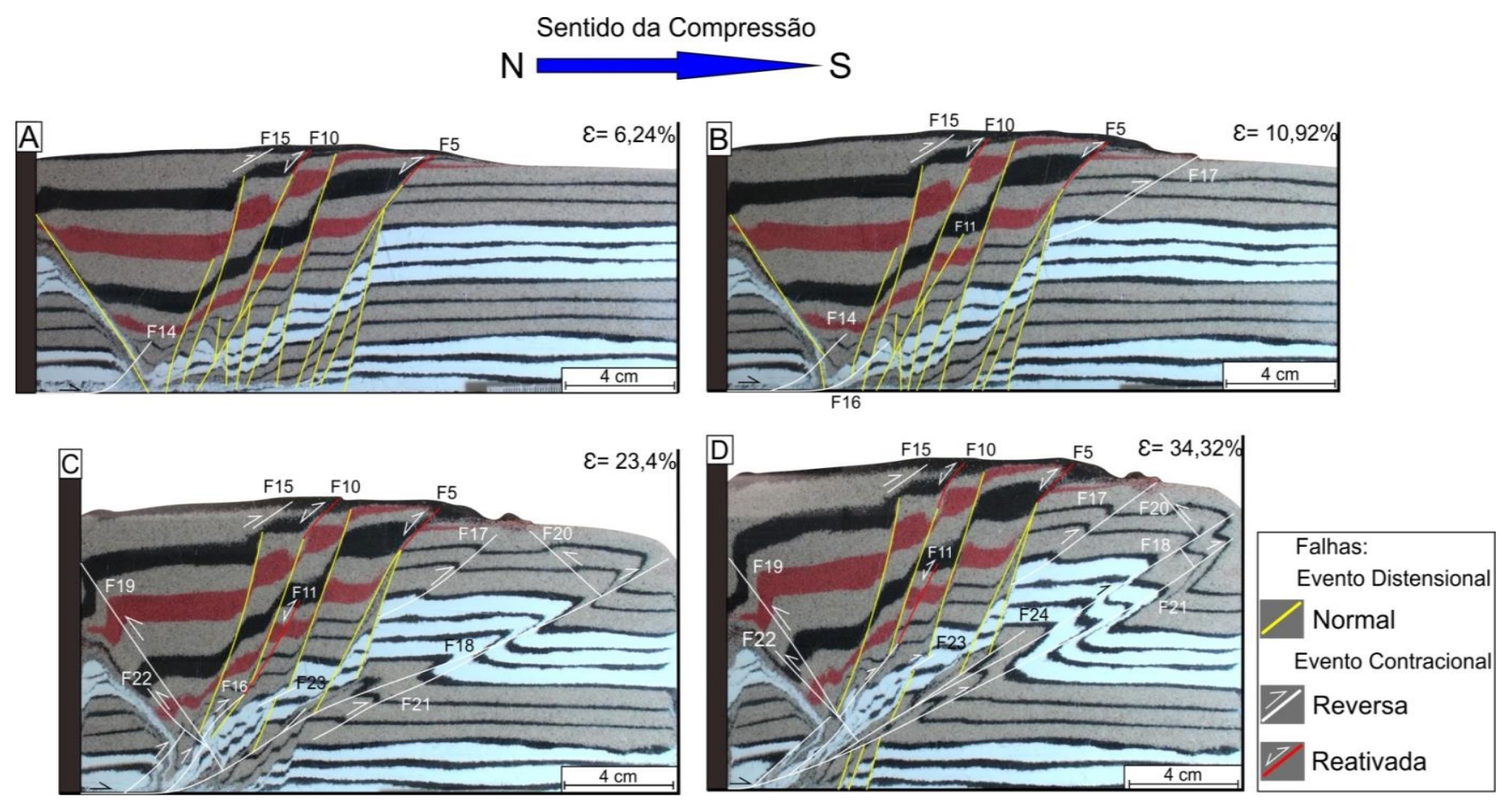

Figura 13. Quatro estágios da deformação D2 em experimento da Série IIB. (A) A deformação inicial foi acomodada pelo descolamento basal, desenvolvimento de falhas reversas F14 e F15 e reativação dos segmentos superiores das falhas F5 e F9. (B) Desenvolvimento de novas falhas reversas com vergência para sul, representadas pelos empurrões F16 e F17. C) Reativação da falha F11 e desenvolvimento das falhas reversas F18 a F23. D) Estágio final do experimento. As falhas reversas seccionaram as falhas normais e se enraizaram no descolamento basal.

A partir deste estágio, observou-se que com o aumento da deformação, a falha reversa F16 se propagou em direção ao topo e quando atingiu a falha normal F11, até então inativa, provoca a sua inversão (Figura 13C). Concomitantemente, houve o desenvolvimento de novos empurrões (F18 e F21), prioritariamente a sequência mais antiga (Figura 13D) e retroempurrões (F19, F20 e F22). A configuração final do experimento mostra que os empurrões coalesceram na porção basal norte do modelo, propagando-se a partir do descolamento basal (Figura 13D).
A superposição de D2 nas estruturas D1 geraram sítios com maior complexidade estrutural. Isto pode ser exemplificado pela evolução das dobras de arrasto junto as falhas originadas em D1. Durante o evento contracional, essas dobras tiveram sua geometria bastante modificada. A figura 14 mostra a evolução de uma dessas dobras, localizada próxima às falhas F2 e F12. Nos primeiros estágios da compressão, a dobra inicialmente aberta, teve o ângulo interlimbo diminuído e ocorreu a translação de seu plano axial. Notou-se 
que a partir de $14 \%$ de encurtamento, a dobra apresentou dois tipos de comportamento. $\mathrm{Na}$ camada de material mais competente (pó de gesso) ocorreu a ruptura da dobra devido o desenvolvimento do empurrão $\mathrm{F} 16$, enquanto que na camada menos competente (areia) essa ruptura não ocorreu. Com a continuação da deformação, houve além da translação, a rotação do plano axial (a partir de $23 \%$ de encurtamento).

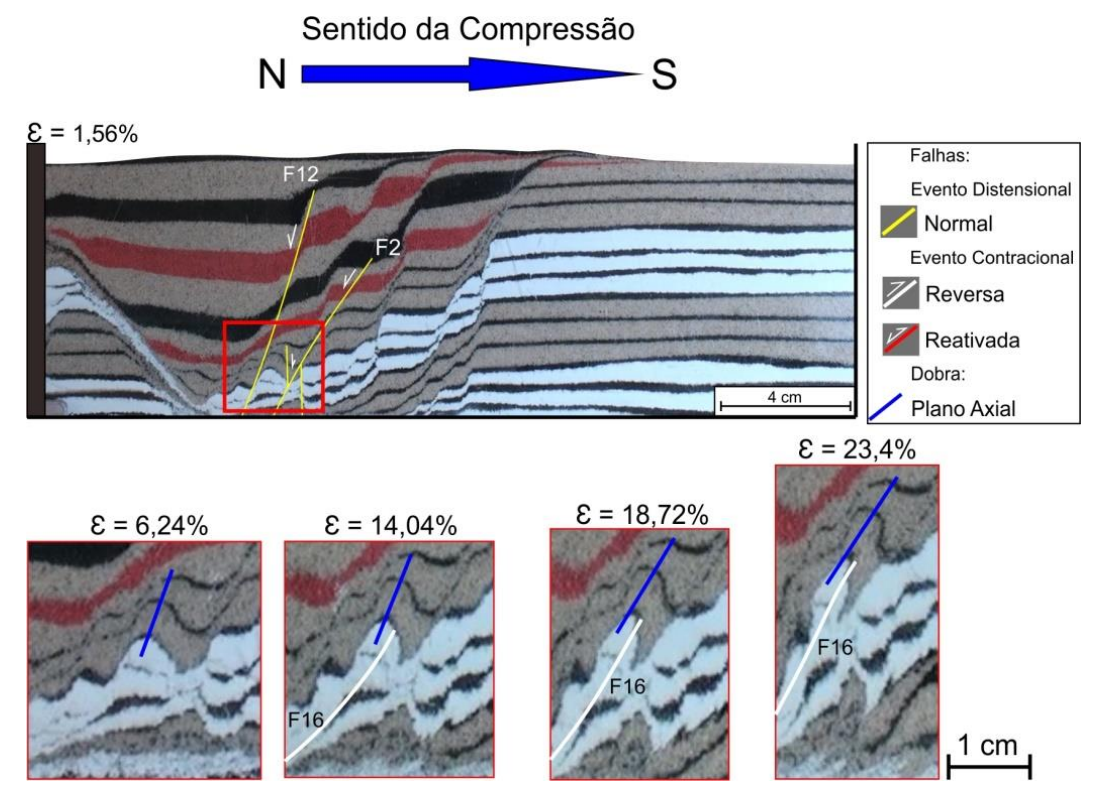

Figura 14. Alguns estágios deformacionais que ilustram o retrabalhamento de dobras D1 (próximo às falhas F2 e F12) durante o evento contracional D2 da Série IIB. A dobra evoluiu de aberta a isoclinal e seu plano axial passou de vertical a inclinado. A geometria final reflete a complexidade estrutural local, dada a superposição D2 a D1.

Nesta série de experimentos os dados obtidos com o PIV foram processados de forma a fornecer além de informações da concentração de strain, os campos de magnitudes do deslocamento do material granular.

Tanto os dados de concentração de strain como os de deslocamento mostram a ausência do desenvolvimento de zonas deformacionais até $1,56 \%$ de encurtamento, que pudessem ser relacionados as falhas (Figura 15A). O deslocamento das partículas ocorreu de forma mais generalizada nos primeiros incrementos deformacionais, principalmente na porção norte do modelo, próximo ao backstop (Figura 15B).

A geração de falhas reversas, representadas por uma faixa de concentração de strain, ocorreu no topo da sequência pré-tectônica de D1 quando o encurtamento atingiu 10\% (Figura 15C). Depois do desenvolvimento desta zona deformacional, os dados de deslocamentos mostraram a compartimentação do modelo em dois grandes setores, separados por uma zona intermediária (Figura 15D). O compartimento superior denominado bloco do Teto tem valores de deslocamento superior a $60 \%$ e corresponde a porção superior do modelo, acima da falha de empurrão mais importante em cada estágio analisado (F17 ou F21). A porção inferior destas falhas, onde o valor de deslocamento ficou entre 0-45\%, foi denominada bloco do Piso, enquanto a porção intermediaria, Zona ZI, teve deslocamento entre 45-60\% (Figura 15D).

Quando o encurtamento ultrapassou os $14 \%$, observou-se que a deformação estava compartimentada em duas zonas deformacionais, que representavam falhas reversas com ângulo aproximadamente $60^{\circ}$, localizadas na camada de areia acima e abaixo da camada de gesso (Figura 15E). Esta compartimentação da deformação, refletindo segmentos do empurrão F21 é confirmada pelos dados de deslocamento, através de um "gap" vertical entre os dois segmentos como ilustrado na figura 15F. Com a junção dos dois segmentos, fruto do aumento da deformação, o gap foi eliminado, restando apenas a zona de concentração de strain (Figuras $15 \mathrm{G}$ e 15H).

Nos últimos incrementos do evento D2, a deformação concentrou-se em nova zona, que representou o desenvolvimento de novas falhas reversas (Figura 15I). Os dados de deslocamento mostraram que nesses estágios, os blocos do Teto e do Piso estavam bem individualizados, em contatos retilíneos, enquanto a zona ZI, com valores intermediários de deslocamento, apresentou-se de forma mais discreta (Figura 15J). 


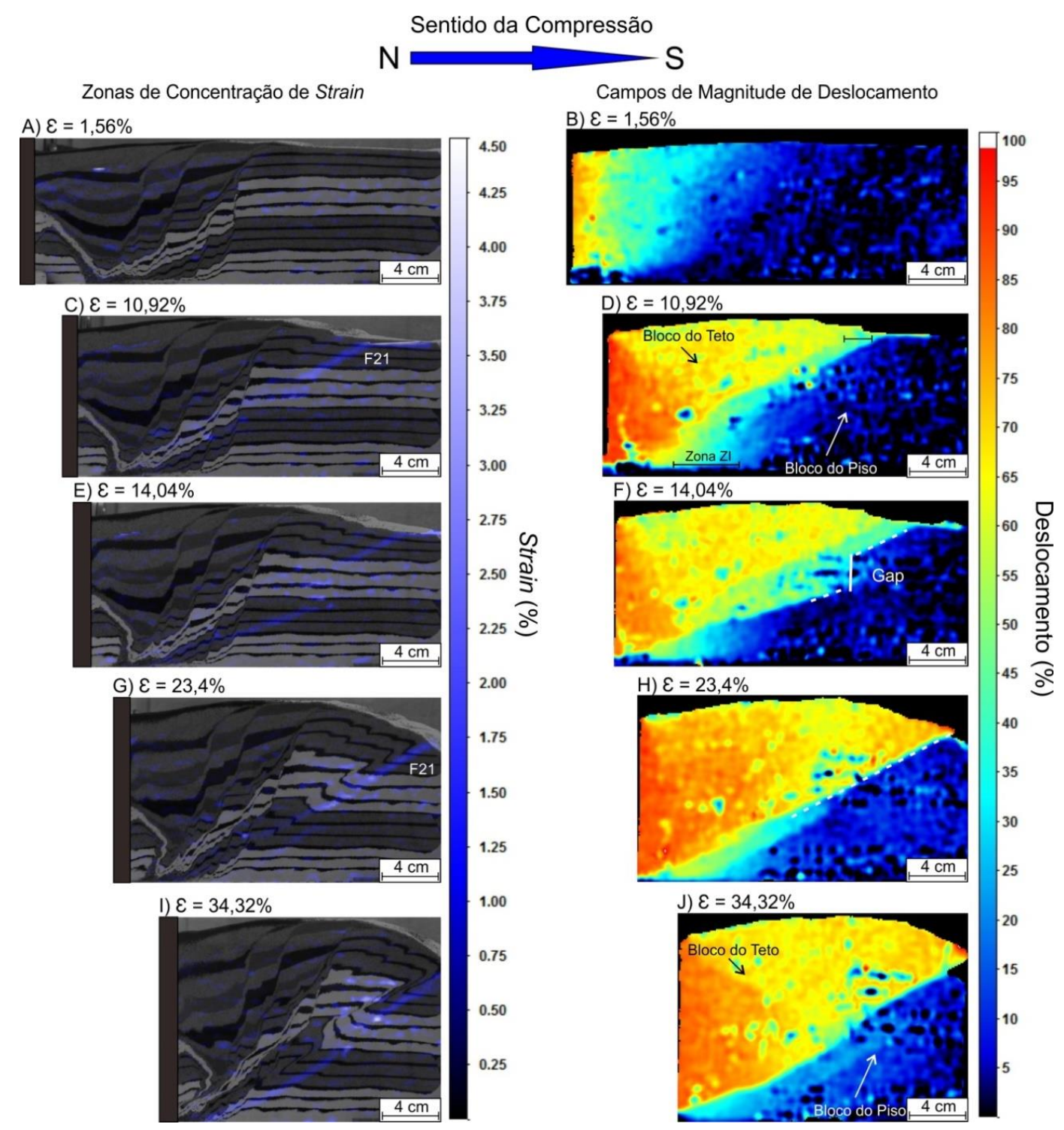

Figura 15. Algumas imagens dos dois tipos de dados obtidos com PIV de alguns incrementos deformacionais do evento D2 em experimento da Série IIB: zonas de concentração de strain (faixas azuis, figuras A, C, E, G e I) e deslocamento das partículas granulares (figuras B, D, F, H e J). (A) Ausência de faixas de concentração de strain. (B) O deslocamento das partículas ocorreu principalmente junto ao backstop, causando compactação do material durante os primeiros incrementos deformacionais. (C) Desenvolvimento de zona deformacional, representando os primeiros empurrões. (D) Os blocos do Teto e do Piso, a partir deste estágio, são individualizados e separados por uma zona de deslocamento intermediário (ZI). (E) Neste estágio, a deformação se concentrou em duas zonas deformacionais, que representaram dois segmentos de falhas reversas. (F) Neste estágio há ausência de deslocamento na camada de gesso entre dois segmentos da falha reversa. (G) Junção das duas zonas deformacionais, desenvolvida nos estágios anteriores, formando única faixa de concentração de strain. (H) Os dados de deslocamento confirmam que os segmentos de falha coalesceram. (I) Geração de novas falhas reversas, representadas por nova zona de concentração de strain. (J) Os blocos do Teto com maior movimentação e do Piso com menor, são bem individualizados e separados pela zona ZI, onde a movimentação foi mais discreta.

\section{Série IIC}

\section{Evento distensional (D1)}

$\mathrm{O}$ início do evento distensional foi marcado pelo desenvolvimento de falhas normais com geometria planar e curva, com ângulo de mergulho variando entre $60^{\circ}$ a subvertical (Figura 16A). Com o aumento da distensão, algumas das novas falhas geradas se enraizaram na parte basal da sequência pré-tectônica, enquanto outras foram limitadas pela falha de borda F2. Como resultado final da deformação D1 o experimento mostrou conjunto de falhas normais de diferentes geometrias, e com algumas falhas de mergulho mais baixo seccionando falhas com mergulho alto, adicionando complexidade a determinados setores do modelo (Figura 16B). 


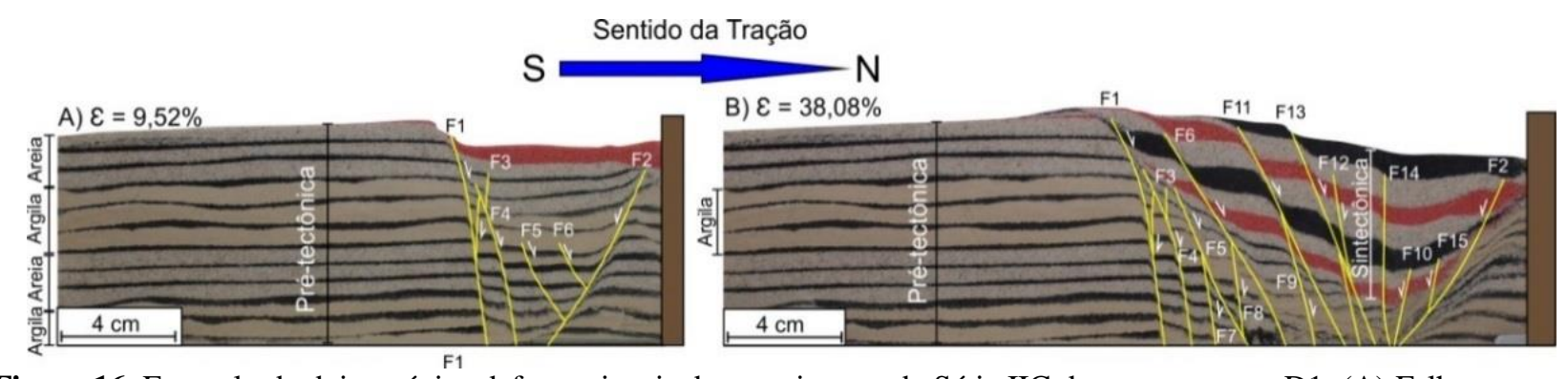

Figura 16. Exemplo de dois estágios deformacionais de experimento da Série IIC durante o evento D1: (A) Falhas normais exibindo sentido de mergulho opostos. (B) Configuração final do experimento, revelando um conjunto de falhas normais com geometria planar ou curva, que se interceptam, evidenciando um arranjo mais complexo na porção sul do modelo.

\section{Evento contracional (D2)}

A reativação, com cinemática reversa, de segmentos de baixo ângulo das falhas normais e o desenvolvimento de pequena falha reversa (F16), no topo da sequência mais jovem marca o início do evento D2 (Figura 17A). O primeiro grande empurrão (F17), desenvolvido em torno de $9 \%$ de compressão, propagou-se a partir do descolamento basal em direção à superfície, no sul do modelo, seccionando as falhas normais pré-existentes (Figura 17B). Com a progressão da deformação novos empurrões foram desenvolvidos paralelamente aos já existentes, além da inversão cinemática da falha F15 (Figura 17C). Nos incrementos finais da deformação D2, os grandes empurrões se interligaram, gerando estruturas tipo "cavalo" tectônicos (Figura 17D). Durante D2, não houve geração de retroempurrões, apenas a reativação de F2 e F15 com cinemática inversa.

$$
\mathrm{S} \stackrel{\text { Sentido da Compressão }}{\mathrm{N}}
$$
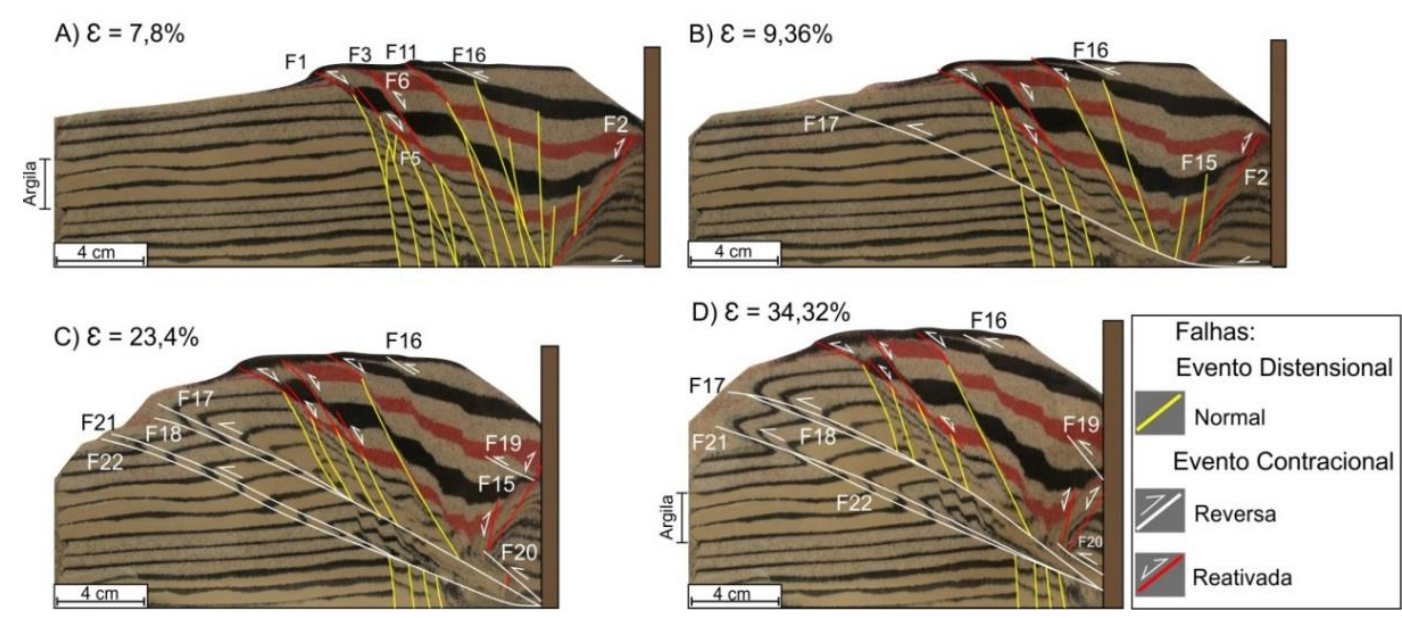

Figura 17. Imagens de alguns estágios deformacionais do evento D2 nos experimentos da Série IIC. (A) Reativação de segmentos de falhas normais, como falhas reversas em $\varepsilon=7,8 \%$. (B) Desenvolvimento do primeiro grande empurrão (F17) em $\varepsilon=9,36 \%$, seccionando as falhas normais pré-existentes. (C) Novos empurrões são desenvolvidos, que se enraizaram no deslocamento basal em $\varepsilon=23,4 \%$. (D) Arquitetura final do modelo $(\varepsilon=34,32 \%)$ mostrando estrutura tipo "cavalo" tectônico delineados por empurrões que seccionam as falhas normais..

Não foi possível visualizar, com os dados do PIV, os primeiros indícios de reativação nos segmentos superiores de algumas falhas. $\mathrm{O}$ registro da primeira zona deformacional ocorreu com cerca de $9 \%$ de compressão e representou uma falha reversa (F17) que seccionou a sequência pré-tectônica de D1 na porção sul do modelo (Figura 18A). Nota-se ainda, neste estágio o início da nucleação de outra zona paralela a esta.

A reativação das falhas normais préexistentes com cinemática reversa torna-se evidente quando a compressão alcançou $12 \%$, com a deformação concentrando-se na falha F2, e o empurrão F17 continuou ativo neste estágio, mostrando um plano com geometria sinuosa. (Figura 18B). No final do evento compressional os dados do PIV mostraram a presença de nova zona de concentração de strain representando nova falha reversa, gerada mais próxima à porção basal do modelo, enquanto as zonas deformacionais desenvolvidas nos estágios anteriores exibem geometria mais planar (Figura 18C). 


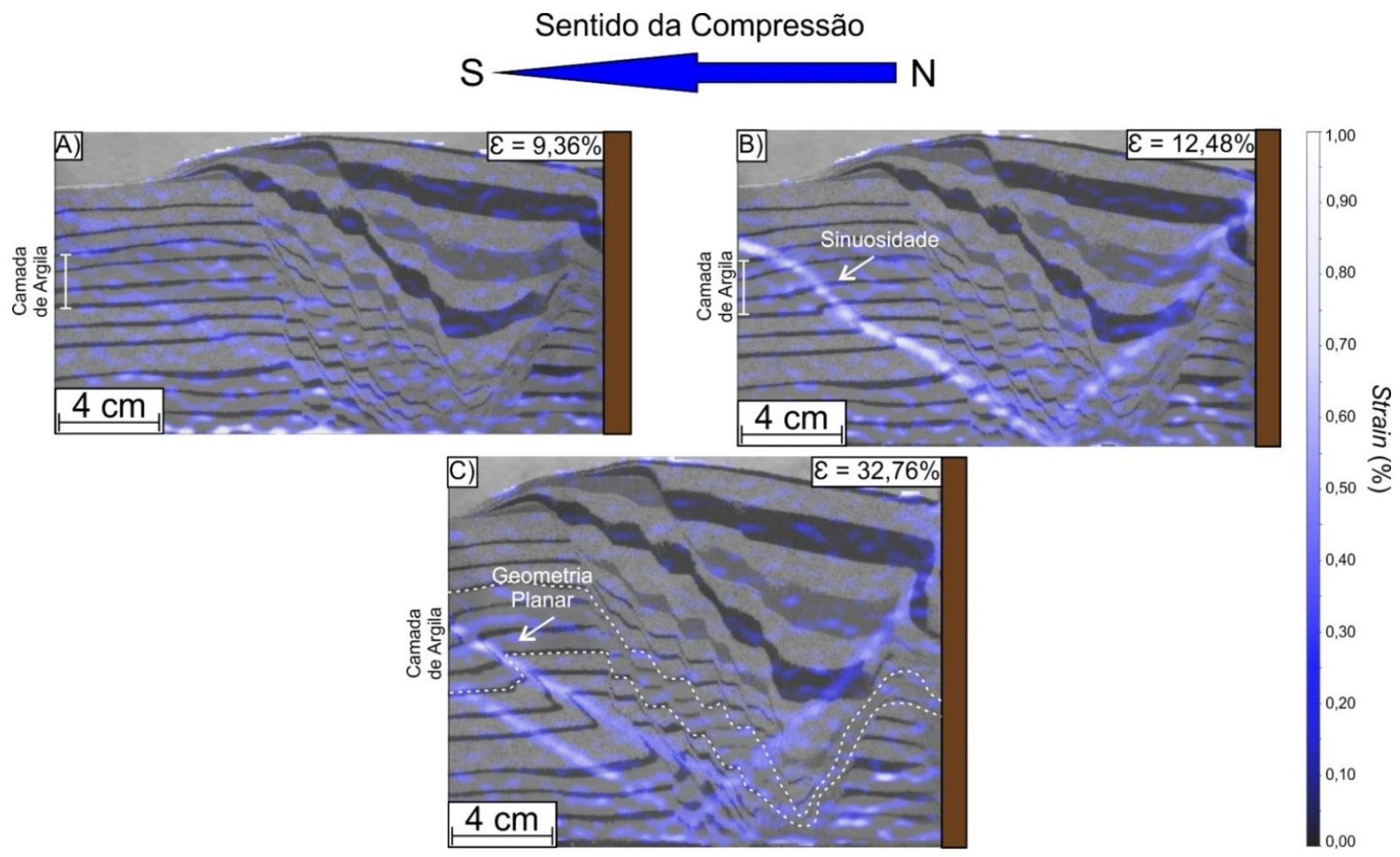

Figura 18. Imagens dos dados de zonas de concentração de strain (faixas azuis) obtidos a partir do sistema PIV, durante o evento contracional (D2) em experimento da Série IIC. (A) Surgimento da primeira zona deformacional (nucleação da falha reversa F17). (B) Zonas deformacionais representando o ápice de movimentação do empurrão F17 e a inversão cinemática da falha normal F2. (C) Desenvolvimento de nova faixa de concentração de deformação, representando o empurrão F21. Notar que, neste estágio a falha F17 apresenta geometria mais planar. O traço pontilhado representa o contorno da camada de argila.

\section{DISCUSSÕES}

\section{Reativação de Falhas}

A inversão positiva dos experimentos realizados neste artigo produziu a reativação de determinadas falhas pré-existentes, com resultados similares aos obtidos por Buchanan \& McClay (1990), na modelagem de inversão de uma falha lístrica. A reativação da falha lístrica, com cinemática reversa, ocorreu em nossos experimentos da Série I (IA e IB), mas apresentaram comportamentos diferentes. Enquanto na Série IA $\left(\alpha=0^{\circ}\right)$ a falha permaneceu ativa durante todo o evento de inversão (D2), na Série IB $\left(\alpha=80^{\circ}\right)$, a reativação não ocorreu nos primeiros incrementos deformacionais (Figura 19), o que difere dos dados de Buchanan \& McClay (1990).

Os dados de rejeito da falha lístrica da Série IA, durante os eventos de distensão e inversão, mostram que esta estrutura teve intensidade de movimentação similar em ambos os eventos, ou seja, o rejeito aumentou gradativamente com o strain (figuras 19A, 19B). Durante a inversão positiva, para que o rejeito atingisse a mesma intensidade daquele adquirido na fase distensional, foi necessário maior strain compressional (figura 19B). O comportamento da falha lístrica dos experimentos da Série IB durante a distensão foi similar àquele dos experimentos da Série IA, diferenciando-se deste, entretanto, por apresentar sempre maior intensidade do rejeito para a mesma percentagem de tração (figura 19C). Durante a inversão, a falha lístrica teve comportamento distinto nas duas séries de experimentos. $\mathrm{Na}$ Série IB a falha lístrica se manteve praticamente inativa até os 14\% de strain (Figura 19D) e, quando ativa, mostrou valores de rejeito bastante inferiores àqueles da Série IA.

Nos experimentos da Série I, a reativação das falhas ocorreu de forma distinta, enquanto na Série IA apenas a falha principal foi reativada, na Série IB, além da falha principal, várias outras falhas normais foram reativadas, apresentando inversão cinemática. Na Série II, independente do contraste reológico presente, a reativação das falhas em D2 foi relativamente limitada. Este número limitado de reativações também é reportado em outros 
trabalhos na literatura (Buchanan \& McClay, 1990; Brun \& Nalpas, 1996; Koopman et al., 1987; Panien et al., 2005 e Ventisette et al., 2006). A reativação de falhas normais com ângulo $\alpha$ superior a $45^{\circ}$, como no caso da Série IB, contrasta com a interpretação de Brun \& Nalpas (1996) e Panien et al. (2005) para quem as falhas normais são reativadas apenas se o ângulo $\alpha$ for menor que $45^{\circ}$, caso contrário a deformação seria acomodada por falhas reversas. Diferentemente dos autores supracitados, e em acordo com nossos resultados, os dados apresentados por Ventisette et al. (2006) mostram que a reativação de falhas normais ocorre independentemente do valor do ângulo $\alpha$.

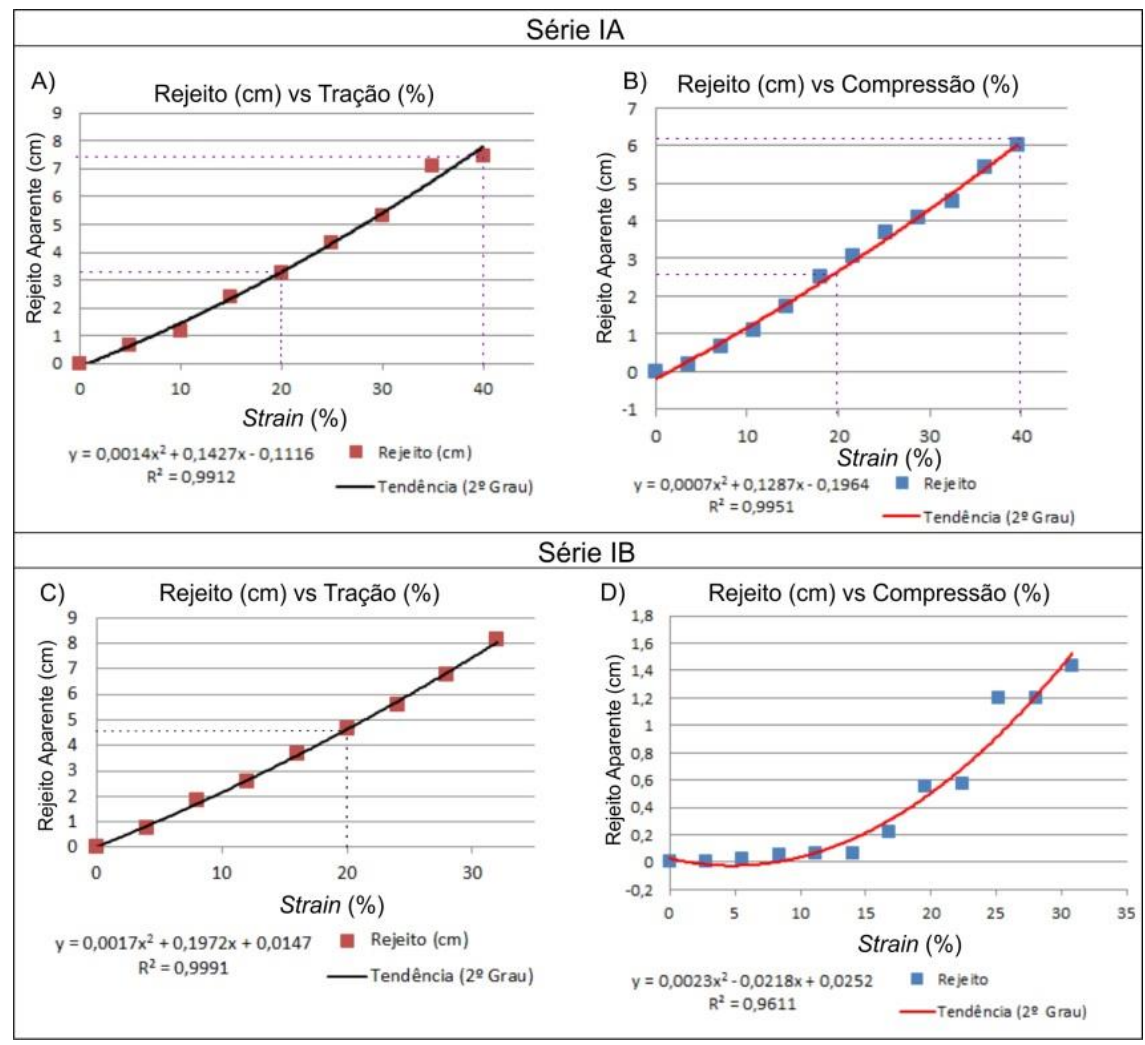

Figura 19. Comportamento (rejeito vs strain) da falha lístrica das Séries IA e IB. Gráficos (A) e (C) durante a distensão (D1) enquanto (B) e (D) durante a contração (D2). (A) e (B) mostram que o rejeito aumenta gradativamente com o aumento do strain. Estes dados sugerem que, para as mesmas condições de contorno, as rochas são mais facilmente deformadas por tração que por compressão. O gráfico (C) mostra os dados do lado Leste do experimento. O rejeito da falha aumentou durante D1 gradativamente com o aumento da tração, enquanto em D2 o rejeito foi próximo a zero nos primeiros incrementos deformacionais (até $14 \%$ de contração), período que a falha permaneceu praticamente inativa. Depois de iniciada a reativação, ocorreu rápido aumento do rejeito.

Durante o evento compressional D2 de nossos experimentos, diferentes padrões estruturais foram gerados, tais como, falhas normais total ou parcialmente reativadas, reativação de segmentos de falhas normais como resultado de coalisão com falha reversa, rotação de segmentos de falhas (com ou sem inversão cinemática) (Figura 20). Nas falhas parcialmente reativadas, observou-se que o segmento reativado, geralmente localizava-se na porção superior do modelo, e possuía ângulo de mergulho menor que o resto da falha. Este fato sugere que, além da orientação, a geometria da falha é um fator importante no controle da inversão do sistema de falha (William et al., 1989).
A reativação cinemática de falhas normais com ângulo de mergulho maior que $60^{\circ}$, como demonstrado nos experimentos da Série IIA, não seria possível em sistema de compressão ortogonal, segundo Brun \& Nalpas (1996). Sibson (1985), entretanto, relata que uma exceção pode ocorrer quando o coeficiente de fricção da falha for inferior a 0.55. As falhas da Série IIA foram reativadas apesar do coeficiente de fricção $(0,70$ para o segundo pico de strenght, Blanco, 2014) da areia utilizada ser mais elevado que àquele sugerido por Sibson (1985). A reativação de falhas normais com ângulo maior que $60^{\circ}$, entretanto, não parece ser raro, ocorrendo também nos experimentos de Konstatinovskaya et al. (2007). 


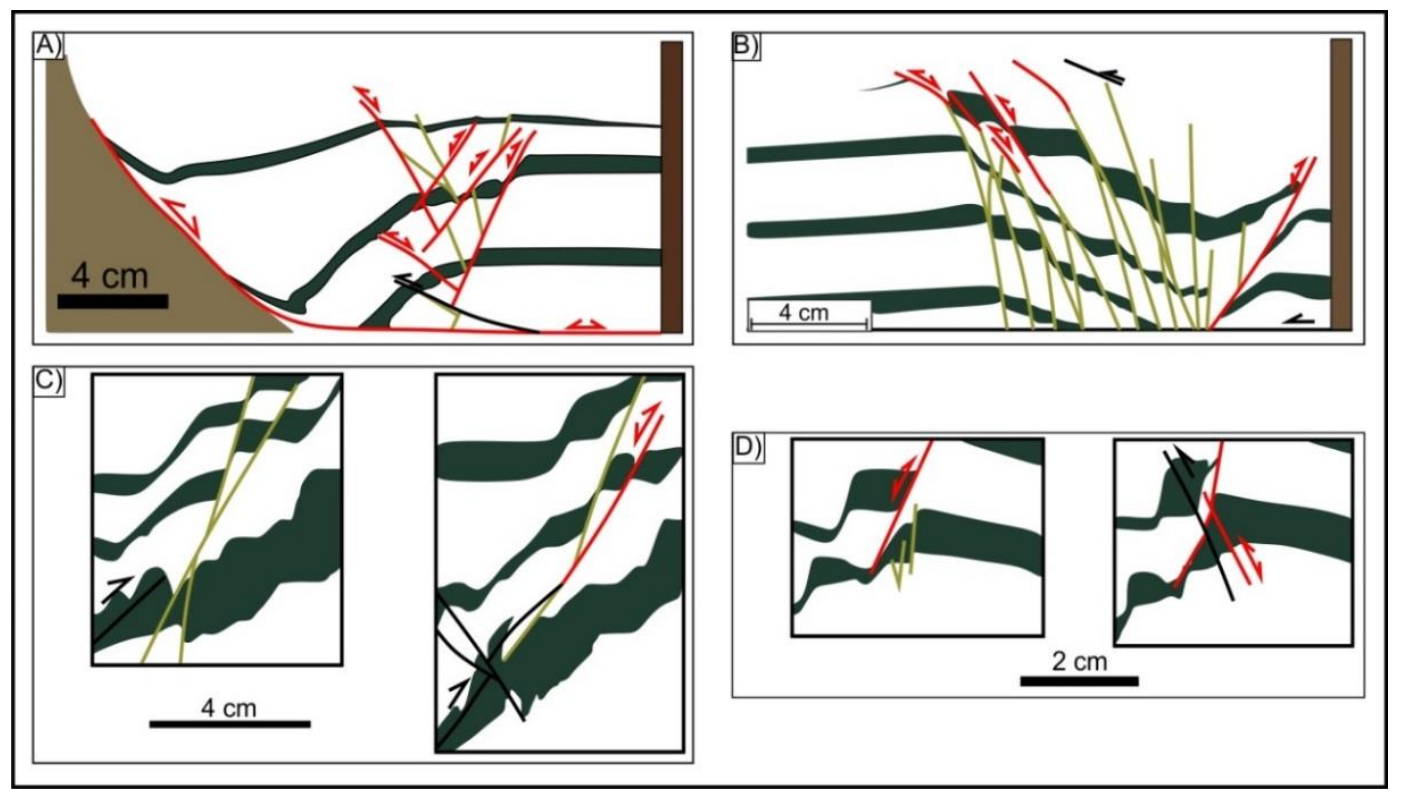

Figura 20. Padrões estruturais gerados pela inversão positiva de um sistema de falhas em nossos experimentos. (A) Falhas normais completamente reativadas. (B) Parcialmente reativadas. (C) Um segmento da falha normal coalesceu com uma falha reversa, sendo reativada. (D) Inversão cinemática de falha normal após ser rotacionada.

Panien et al. (2005) usa o argumento de Sibson (1985) para explicar o fato de determinadas falhas, mesmo com geometria e orientação favoráveis não são reativadas, sugerindo que o tipo de material granular utilizado pode influenciar na predisposição de determinadas falhas reativarem. A descontinuidade reológica entre camadas controla, em determinada escala, a geometria das falhas que, quando atravessam estratos mais competentes, apresentem geometria planar e ângulo de mergulho mais elevado do que nos estratos menos competentes (Oliveira \& Alves da Silva, 2016). Esta situação também é ilustrada na Série IIB.

\section{Arquitetura Estrutural}

O evento de inversão positiva D2 produziu diferenças significativas na arquitetura estrutural final dos modelos desenvolvidos neste artigo. Nos experimentos da Série I, a configuração final exibiu arquitetura que incluía tanto a falha principal como as falhas normais que delimitam a estrutura grabenforme reativadas. Empurrões e retroempurrões apresentaram-se enraizados na porção basal da falha lístrica, ou se desenvolveram na parte superior da sequência, propagando-se em direção à base da estrutura grabenforme. Por sua vez, a Série IA, apresentou arcabouço estrutural onde, entre as falhas geradas em D1, apenas a falha principal foi reativada. Junto à falha lístrica, as camadas sintectônicas a D1, com crescimento de seção, revelam a inversão cinemática através da modificação de sua geometria e o desenvolvimento de estrutura tipo arpão (Figura 3). Esse tipo de comportamento é descrito na natureza e mapeado por sísmica na plataforma Leste de Sunda (Bonini et al., 2012).

Os experimentos da Série II foram muito similares àqueles construídos por Panien et al. (2005) que utilizando materiais com reologia diferente mostraram que, dependendo do material utilizado, o ângulo de mergulho dos empurrões pode variar entre $23^{\circ}$ a $39^{\circ}$. Nos experimentos da Série IIA, onde utilizamos apenas a areia, a arquitetura final do modelo mostra falhas normais completamente reativadas e a presença de empurrões e retroempurrões que seccionam a porção basal da estrutura grabenforme. Nos modelos contendo camadas de pó de gesso (Série IIB), observou-se que apenas alguns segmentos de falhas normais sofreram reativação, e que os empurrões coalesceram no deslocamento basal. Nesta série de experimento, houve o desenvolvimento de dobras de arrasto durante o evento D1 que, com o início da inversão positiva, passam por processo de encurtamento. Ao longo do evento contracional essas dobras foram deformadas, comportando-se de forma distinta quando desenvolvida em material mais e menos competente. Na camada de pó de gesso as dobras sofreram ruptura, relacionada ao desenvolvimento de um empurrão, enquanto que na camada de areia, o plano axial foi rotacionado, sem rupturas. 
Embora com modificação na estratigrafia reológica, o arranjo estrutural dos experimentos da Série IIC ao final da deformação D2, foi muito similar ao da Série IIB. Segmentos de falhas normais, principalmente na parte superior da sequência, foram reativados e os empurrões coalesceram entre a passagem da camada de areia para argila, ressaltando a influência do contraste reológico no desenvolvimento e reativação de falhas. $\mathrm{O}$ processo de reativação atingindo apenas partes (segmentos) de determinadas falhas, como na Série II, geralmente ocorre quando o ângulo de mergulho da falha diminui, de forma similar àquelas existentes na seção offshore do Mar Adriático (Bonini et al. 2012).

\section{LOCALIZACÃO E CONCENTRACÃO DO STRAIN}

Os vetores de velocidade absoluta utilizados neste trabalho (Figura 21A) possibilitaram a visualização e análise de strain durante o início da compressão e mostraram que a deformação foi absorvida primeiramente pela compactação do material granular, e que, só após este processo, ocorreu a reativação e/ou criação de novas falhas.

\begin{tabular}{|c|c|c|c|}
\hline \multicolumn{3}{|c|}{ Tipos de dados } & Interpretação \\
\hline \begin{tabular}{l|l}
$\frac{\pi}{2}$ \\
$\frac{0}{0}$ \\
$\frac{0}{4}$ \\
0 \\
$\frac{0}{0}$ \\
$\frac{\pi}{0}$ \\
$\frac{0}{0}$ \\
$\frac{0}{0}$
\end{tabular} & $\varepsilon=5,6 \%$ & 䙐 & $\begin{array}{l}\text { Os vetores mostram o deslocamento do } \\
\text { material granular. Neste caso, a deformação } \\
\text { foi absorvida primeiramente pela compac- } \\
\text { tação do material. Posteriormente ocorreu } \\
\text { a reativação das falhas normais e o desen- } \\
\text { volvimento de falhas reversas. }\end{array}$ \\
\hline & $\varepsilon=18,7 \%$ & 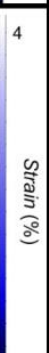 & $\begin{array}{l}\text { A distribuição do strain em zonas especí- } \\
\text { ficas indicam a presença das falhas ativas } \\
\text { no incremento deformacional. Mostra os } \\
\text { estágios iniciais de nucleação de falhas, } \\
\text { não captados por fotografias convencionais. } \\
\text { Durante a inversão positiva foi possível veri- } \\
\text { ficar que algumas falhas alternam momen- } \\
\text { tos ativos com inativos. }\end{array}$ \\
\hline 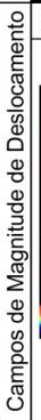 & Bloco do Teto & 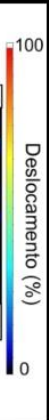 & $\begin{array}{l}\text { Este tipo de dado mostra a individualização } \\
\text { de zonas de movimentação de massa nos } \\
\text { blocos do teto e do piso da falha. A movi- } \\
\text { mentação no hanging wall é bem mais im- } \\
\text { portante. A zona intermediària ( } \mathrm{ZI} \text { ) torna- } \\
\text { se mais discreta a medida que a deforma- } \\
\text { ção aumenta. }\end{array}$ \\
\hline
\end{tabular}

Figura 21. Principais tipos de dados obtidos com o sistema PIV, durante a inversão de um sistema de falhas em nossos experimentos. (A) Mostra a trajetória e velocidade de cada partícula granular durante a deformação. A cor das setas indica a velocidade de movimentação das partículas. (B) Mostra regiões onde as falhas, ou segmentos de falhas, encontram-se ativas através da discriminação de zonas de concentração de strain. (C) Mostra a compartimentação da região falhada através da magnitude do deslocamento das partículas granulares.

A distribuição e concentração do strain durante o evento D2 (Figura 21B) forneceram subsídios para a análise da nucleação e desenvolvimento de falhas no processo de inversão tectônica, mostrando adicionalmente os períodos de atividade e inatividade, este último ocorrendo geralmente quando da nucleação de outra falha nas proximidades. Assim, foi possível observar que a falha lístrica da Série IB, durante sua inversão, alternou estágios ativos e inativos. Outras falhas também tiveram este comportamento, a exemplo da falha F11 da Série IIB (Figura 11). Fato importante a remarcar é que estes dados fornecem o momento exato da nucleação da falha, o que não é observado por outros meios mais comumente usados na modelagem. Dados de magnitude deslocamento foram obtidos/analisados apenas para os 
experimentos da Série IIB (Figura 21C). Este tipo de dado mostra com bastante clareza, a compartimentação e individualização das regiões acima e abaixo da falha, (blocos do teto e do piso) separados por uma zona intermediaria (ZI) que marca o arrefecimento da movimentação do material. Este tipo de dado mostrou ainda que durante a inversão positiva, as camadas de comportamento mais competentes (pó de gesso, no presente caso) podem gerar "gaps" verticais entre segmentos de falhas reversas.

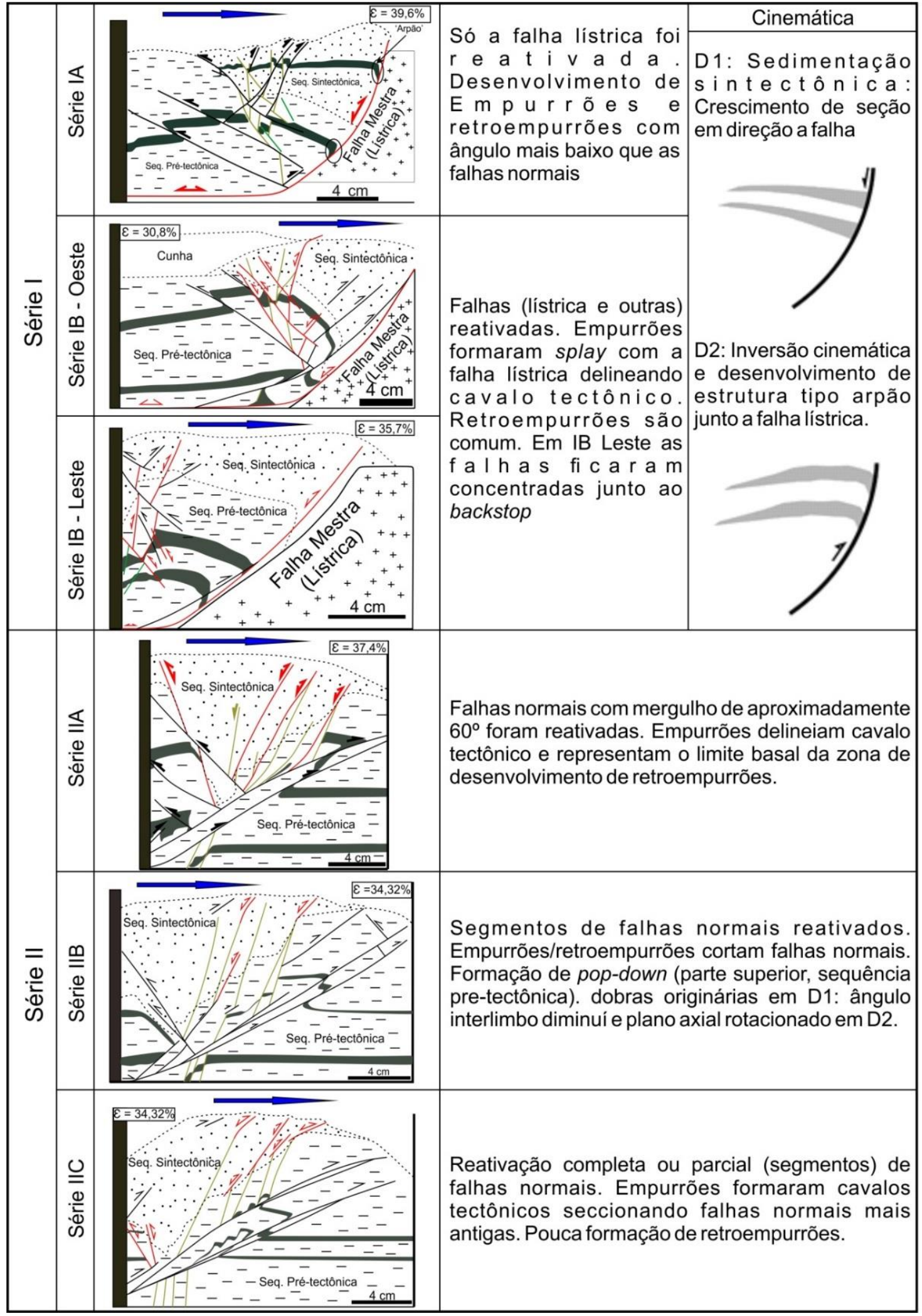

Figura 22. Principais características da arquitetura estrutural final da inversão positiva dos sistemas de falhas gerados em cada experimento realizado neste artigo. 


\section{CONCLUSÃO}

Os experimentos realizados simularam a inversão positiva de falhas normais formadas em um evento distensional (D1) e a geração de novas estruturas durante um evento contracional (D2) subsequente.

Fatores como a estratigrafia mecânica, orientação e o posicionamento das falhas no sistema sob deformação influenciam na arquitetura estrutural da bacia invertida. Algumas das principais características desta arquitetura ao final do evento contracional, em cada uma das séries de experimentos realizadas, são mostradas de forma resumida na figura 22.
Os dados fornecidos pelo PIV mostraram que esta ferramenta é importante na análise da história deformacional de determinada área, simulada em laboratório. Dependendo da estrutura ou processo a ser estudado, os diferentes dados obtidos com o PIV, podem ser bastante úteis na localização de zonas com concentração de strain e discriminação das estruturas que estavam ativas ou não, durante o evento analisado. Esse tipo de informação é extremamente útil, por exemplo, para se conhecer o papel de determinadas estruturas durante a migração de fluidos (hidrocarbonetos ou fluidos hidrotermais).

\section{AGRADECIMENTOS}

L. K. A. de Sousa agradece a CAPES e A.J.P.C. Blanco ao PRH22(ANP) pelas bolsas de mestrado e doutorado, respectivamente, no Programa de Pós-Graduação em Geodinâmica e Geofísica (PPGG) da Universidade Federal do Rio Grande do Norte (UFRN). Os autores agradecem também aos revisores anônimos que contribuíram para a melhoria deste artigo. O Laboratório de Modelagem Física do PPGG recebeu apoio do CENPES/PETROBRAS

\section{REFERÊNCIAS}

ADAM, J.; URAU, J. L.; WIENEKE, B.; ONKEN, O.; PFEIFFER, K.; KUKOWSKI, N.; LOHRMANN, J.; HOTH, S.; VAN DER ZEE, W.; SCHMATZ, J. Shear localization and strain distribution during tectonic faulting-new insights from granular-flow experiments and high-resolution optical image correlation techniques. Journal of Structural Geology, v. 27, p. 283-301, 2005.

AMILIBIA, A.; MCCLAY, K. R.; SÀBAT, F.; MUÑOZ, J. A.; ROCA, E. Analogue modelling of inverted oblique rift systems. Geologica Acta, v. 3, n. 3, p. 251-271, 2005.

BLANCO, A. J. P. C. 2016. Modelagem Estrutural física da formação das margens equatorial e leste do Brasil durante a ruptura do Gondwana. 2016, 35 p. Inédito. Seminário de qualificação II (Mestrado em Geociências) - Programa de Pós-Graduação em Geodinâmica e Geofísica, Universidade Federal do Rio Grande do Norte.

BONINI, M.; SANI, F.; ANTONIELLI, B.; Basin inversion and contractional reactivation of inherited normal faults: a review based on previous and new experimental models. Editora Elsevier. Tectonophysics, v. 522-52, p. 55-88, 2012

BROSSARD, C.; MONNIER, J. C.; BARRICAU, P.; VANDERNOOT, F. X.; LE SANT, Y.; CHAMPAGNAT, F.; LE BESNERAIS, G. Principles and applications of particle image velocimetry. Journal AerospaceLab, v. 1, p. $1-11,2009$

BRUN, J. P. \& NALPAS, T. Graben inversion in nature and experiments. Tectonics, v. 15, p. 677-687, 1996.

BUCHANAN, P.G. \& MCCLAY, K.R. Sandbox experiments of inverted listric and planar fault systems. Tectonophysics, v. 188 , p. $97-115,1991$.

COOPER M.A. \& WILLIAMS G.D. (Editores), Inversion Tectonics. 44. Geological Society of London Special Publication. 375 p., 1989.

COSTA, J. B. S.; HASUI, Y.; PINHEIRO, R. V. L. Bacias Sedimentares: aspectos gerais da geometria, desenvolvimento, preenchimento e inversão. Editora Universitária Universidade Federal do Pará, Belém, 116 p., 1992.
DUBOIS, A.; ODONNE, F.; MASSONNAT, G.; LEBOURG, T.; FABRE, R. Analogue modelling of fault reactivation: tectonic inversion and oblique remobilization of grabens. Pergamon. Journal of Structural Geology, v. 24, p. 1741-1752, 2002

GOMES, C. J. S.; FILHO, A. D.; POSADA, A. M. A.; SILVA, A. C. The role of backstop shape during inversion tectonics physical models. Anais da Academia Brasileira de Ciências, v. 82 , n. 4, p. $997-1012,2010$

GOMES, C. J. S.; MARTINS-NETO, M. A.; VALÉRIA, E.; RIBEIRO, V. E. Positive inversion of extensional footwalls in the southern Serra do Espinhaço, Brazil - insights from sandbox laboratory experiments. In: Annals of the Brazilian Academy of Sciences, v. 78, n. 2, p. 331-344. 2006

KELLER, J. V. A. \& MCCLAY, K. R. 3D sandbox models of positive inversion. In: Buchanan J. G. \& Buchanan, P.G. (Eds.), Basin Inversion, 88. Geological Society of London Special Publication, p. 137-146, 1995

KONSTATINOVSKAYA, E.A.; HARRIS L, B.; POULIN, J.; IVANOV, G. M. Transfer zones and fault reactivation in inverted rift basins: Insights from physical modelling. Tectonophysics, v. 441, p. 1-26, 2007.

KOOPMAN, A.; SPENKSNIJDER, A.; HORSFIELD, W. T. 1987. Sandbox model studies of inversion tectonics. Elsevier Science Publishers B. V. Amsterdam. Tectonophysics, v. 137, p. 379-388, 1987.

MCCLAY, K. R. The geometries and kinematic of inverted fault systems: a review of analogue model studies. In: Buchanan J. G. \& Buchanan P.G. (Editores.), Basin Inversion. Special Publication, 88. Geological Society, London, p. 97-118, 1995

NALPAS, T.; LE DOUARAN, S.; BRUN, J. P. P.; UNTERNEHR, P.; RICHERT, J. P. Inversion of the Broad Fourteens Basin (offshore Netherlands), a small-scale model investigation. Editora Elsevier. Sedimentary Geology, v. 95, p. 237-250, 1995

OLIVEIRA, M. E. \& ALVES DA SILVA, F.C. A importância da estratigrafia mecânica no desenvolvimento de falhas e juntas em contexto de bacias sedimentares: Contribuição de 
modelos experimentais. Revista de Geologia da USP. Série Científica, v. 16, n. 3, p.39-55, 2016.

PANIEN, M.; SCHREURS, G.; PFIFFNER, A. Sandbox experiments on basin inversion: testing the influence of basin orientation and basin fill. Elsevier Ltda. Journal of Structural Geology, v. 27, p. 433-445, 2005.

PINTO L., MUÑOZ C., NALPAS T., CHARRIER R. Role of sedimentation during basin inversion in analogue modelling. Editora Elsevier, Journal of Structural Geology, v. 32, p. 554$565,2010$.

SIBSON R. H. A note on fault reactivation. Journal of Structural Geology, v. 7, p. 751-754, 1985.

VENTISETTE, C. D.; MONTANARI, D.; SANI, F.; BONINI, M. Basin inversion and fault reactivation in laboratory experiments. Editora Elsevier. Journal of Structural Geology, v. 28, p. 2067-2083, 2006.

WHITE, D. J.; TAKE, W. A.; BOLTON, M. D. Measuring soil deformation in geotechnical models using digital images and PIV analysis. In: $10^{\mathrm{TH}}$ INTERNATIONAL CONFERENCE ON COMPUTER METHODS AND ADVANCES IN
GEOMECHANICS, 10, 2001, Tucson, Arizona. Resumo Expandido. Balkema, Rotterdam, p. 997-1002, 2001.

WILLIAMS, G. D.; POWELL, C. M.; COOPER, M. A. Geometry and kinematics of inversion tectonics. Geological Society, London, Special Publications, v. 44, p. 3-15, 1989.

WOLF, H.; KÖNIG, D.; TRIANTAFYLLIDIS, T. Experimental investigation of shear band patterns in granular material. Journal of Structural Geology, v. 25, p. 1229-1240, 2003.

YAMADA, Y. \& MCCLAY, K. R. Application of geometric models to inverted listric fault systems in sandbox experiments. Paper 1: 2D hanging wall deformation and section restoration. Journal of Structural Geology, v. 25, p. 1551-1560, 2003. 